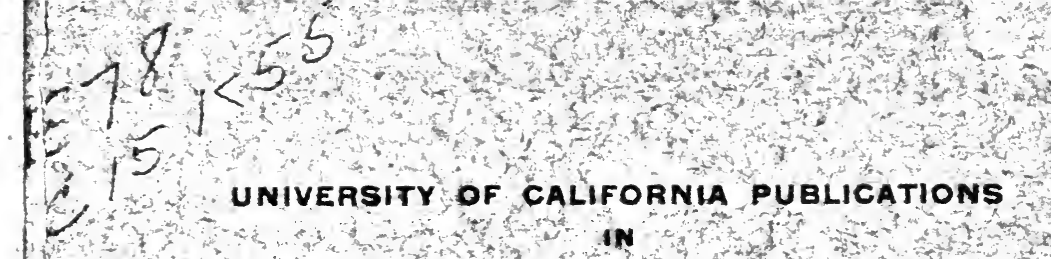

AMERICAN ARCHAEOLOGY AND ETHNOLOGY

Vol. 13, No. 8, pp. 259-328, 4 maps in text

November 21,1922

\title{
ELEMENTS OF CULTURE IN NATIVE
}

CALIFORNIA

BX

A. L. KROEBER

11

UNIVERSITY OF CALIFORNIA PRESS

BERKELEY, CALIFORNIA 


\section{UNIVERSITY OF CAITFORNIA PUBLICATIONS}

\section{DEPARTMENT OF ANTHROPOLOGY}

The following publications dealing with archaeological and ethnological subjects issaed ender the direction of the Department of Anthropology are sent in exchange for the purbit cations of anthropological departments and museums, and for journals devoted to general anthropology or to archaeology and ethnology. They are for sale at the prices stated. Exchanges should be directed to The Exchange Department, University Iibrary, Berkeley, Callfornia, U. S. A. All orders and remittances should be addressed to the University of Callformia Press.

AMEEICAN AKCHADUJJOGY AND ETHNOLOGY.-A. I. Kroeber, Editor. Prices, Volume 1, \$4.25; Volumes 2 to 11, inclusive, $\$ 3.50$ each; Volumes 12 to 17, inclusive, \$5. 10 easin; Tolunie 18, \$4.00.

Uited as Univ. Calle. Pabl. Am. Arch. Bthn.

Prtoo

Vol 1. 1. Life and Culture of the Hupa, by Pling Earle Goddard. Pp. 1-88, plates 1-30. September, 1903

2. Hupa Texts, by Pliny Earlo Goddard. Pp. 89-368. March, 1904 Index, pp. 369-378.

Vol. 2. 1. The Exploration of the Potter Creek Cave, by William J. Sinclair. Pp. 1-27, plates 1-14. April, 1904

2. The Ianguages of the Cosst of Callfornia Bouth of Ban Franciaco, by A. I. Kroeber. Pp. 29-80, with a map. June, 1904

3. Types of Indian Cultare in Callfornia, by A. I. Kroeber. Pp. 81-103. June, 1904

1. Basket Designs of the Indians of Northwestern Callfornia, by $\boldsymbol{\Lambda}$. $\mathrm{I}$. Kroeber. Pp. 105-164, plates 15-21. January, 1905

5. The Yokuts Language of South Central Callfornia, by A. I. Broeber. Pp. 165-377. January, 1907 Index, pp. 379-392.

Vol. s. The Morphology of the Hupa Language, by Pliny Earle Goddard. 344 pp. June, 1905

Vol 4. 1. The Earliest Historical Relations between Mexico and Japan, from original documents preserved in Spain and Japan, by Zelia Nuttall. Pp. 1-47. April, 1906

2. Contribution to the Physical Anthropology of Callfornia based on collections in the Department of Anthropology of the TTniversity of Callfornis, and in the U. S. National Museum, by Ales Hrdlicka. Pp. 49-64, with 5 tables, plates 1-10, and map. June, 1906

3. The Shoshonean Dialects of California, by A. I. Kroeber. Pp. 65-166. February, 1907

4. Indian Myths from South Central California, by A. I. Kroober. Pp. 167 . 250. May, 1907

5. The Washo Language of East Central Catifornia and Nevads, by A. I.

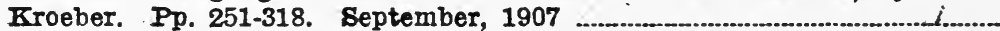

6. The Religion of the Indians of Callfornia, by A. I. Kroeber. Pp. 319-356. September, 1907 Index, pp. 357-374.

V01. 5. 1. The Phonology of the Hupa Ianguage; Part $I$, The Individual Sounds, by Pliny Earle Goddard. Pp. 1-20, plates 1-8. March, 1907

2. Navaho Myths, Prayers and Songs, with Texts and Translations, by Wash ington Matthews, edited by Pliny Iarlo Goddard. Pp. 21-63. September, 1907

3. Kato Texts, by Pliny Earle Goddard. Pp. 65-238, plate 9.' December, 1909

4. The Material Culture of the Klamath Lake and Modoc Indians of Northeastern Callfornia and Southern Oregon, by B. A. Barrett. Pp. 239-292, plates 10-25. June, 1910

5. The Chimariko Indians and Language, by Boland B. Dixon. Pp. 293-380. Angust, 1910 Index, pp. 381-384.

Val. 6. 1. The Ethno-Geography of the Pomo and Nelghboring Indians, by Bamnel Alfred Barrett. Pp. 1-332, maps 1-2. February, 1908

2. The Geography and Dialects of the Miwok Indians, by Samuel Alfred Barrett. Pp. 333-368, map 3.

8. On the Evidence of the Occupation of Certain Regions by the Miwok Indians, by A. I. Kroeber. Pp. 369-380.

Nos, 2 and 3 in one cover. February, 1908 Index, pp. $381-400$.

Vol. 7. 1. The Emeryville Shellmound, by Max Uhle.' Pp. 1-106, plates 1-12, with 38 text figures. June, 1907

2. Recent Investlgations bearing upon the Question of the Occurrence of Neocene Man in the Aurferous Gravels of Callfornia, by William.J. Sinclair. Pp. 107-130, plates 13-14. February, 1908 
UNIVERSITY OF CALIFORNIA PUBLICATIONS

\section{ELEMENTS OF CULTURE IN NATIVE CALIFORNIA}

BY

A. L. KROEBER

CONTENTS PAGE

Introduction $\quad 260$

Arts of life

Dress...

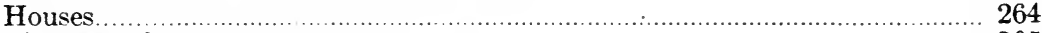

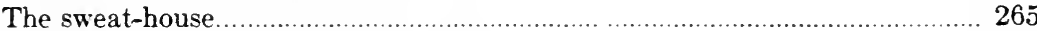

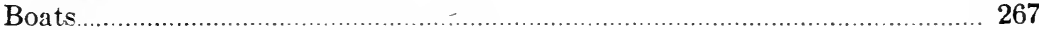

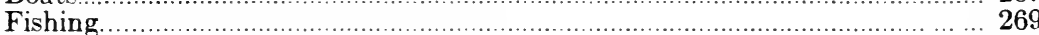

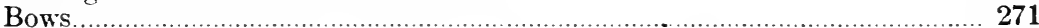

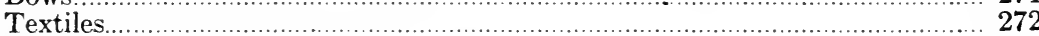

Pottery .

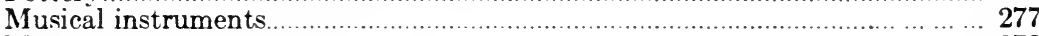

Money

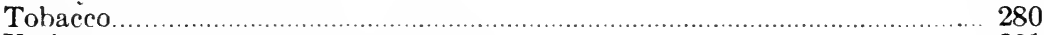

Various 281

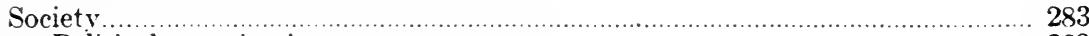

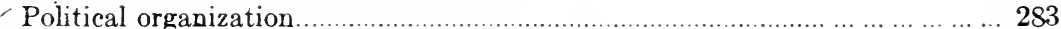

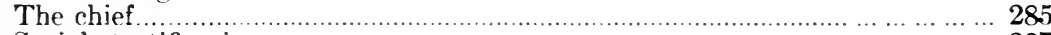

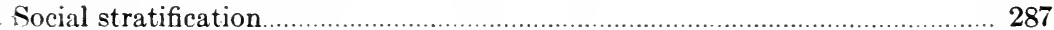

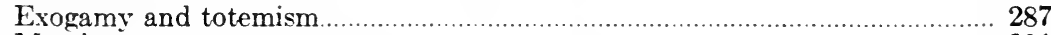

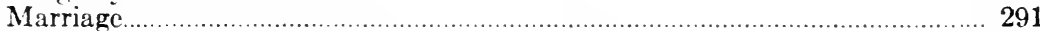

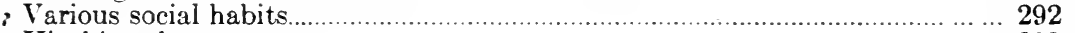

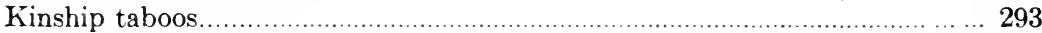

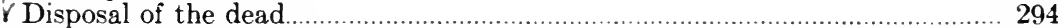

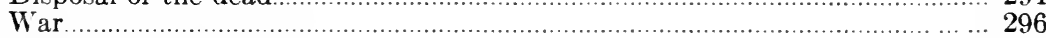

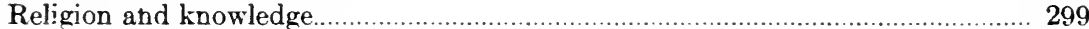

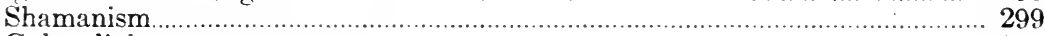

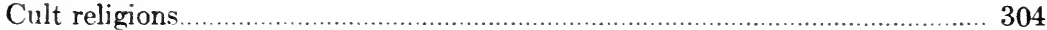

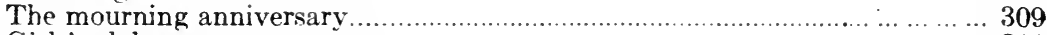

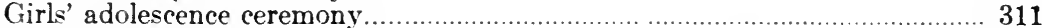

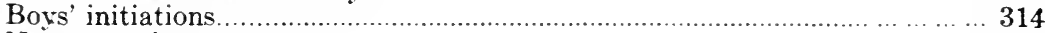

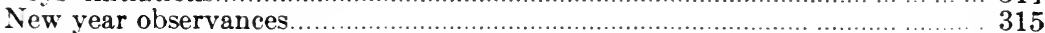

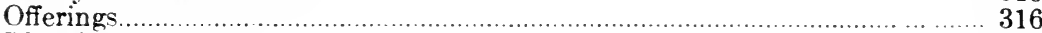

The ghost dance.

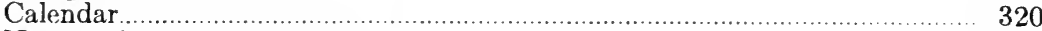

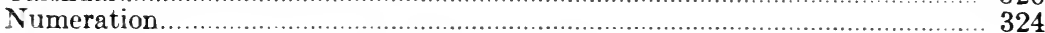

MAPS, TABLES

Map 1. Native Tribes, Groups, Districts, and Families of California in 1770, opp. 260

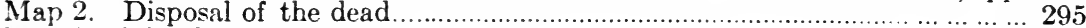

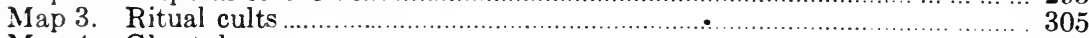

Map 4. Ghost dances................................................................................. 321

Table 1. The adolescence ceremony for girls......................................... 312

Table 2. Ritual numbers and methods of numeration ......................................... 325 


\section{INTRODUCTION}

These pages are intended for readers whose ethnographic interests are at once sufficiently broad and sufficiently intense to absorb local data presented in summarized fashion. The sketch does not endeavor a systematic presentation of the native Californian cultures. Information that is abundant or suggestive in certain, aspects, such as its distributional significance, is outlined and discussed. On the other hand, subjects like magic and ritual dress on which knowledge is irregular, miscellaneous, or complicated by intricate considerations have been omitted. Extra-Californian comparisons have been instituted rather sparingly. The purpose has been not so much to relate California as a unit to other American cultures, as to outline the internal relations of the primitive civilization of the area. Data are not cited in detail. Such as are not to be found in this series of publications and the other literature on the subject are taken from a manuseript volume on the Indians of California prepared for and in possession of the Bureau of American Ethnology; to the courtesy of which institution the issue of the present discussion is due.

Map 1 shows the territory of all the ethnic groups in California.

\section{ARTS OF LIFE}

\section{DRESS}

The standard clothing of California, irrespective of cultural provinces, was a short skirt or petticoat for women, and either nothing at all for men or a skin folded about the hips. The breechclout is frequently mentioned, but does not seem to have been aboriginal. Sense of modesty among men was slightly developed. In many parts all men went wholly naked except when the weather enforced protection, and among all groups old men appear to have gone bare of clothing without feeling of impropriety. The women's skirt was everywhere in two pieces. A rather narrow apron was worn in front. A larger back piece extended around at least to the hips and frequently reached to meet the front apron. Its variable materials were of two kinds : buckskin and plant fibers. Local supply was the chief 
factor in determining choice. If the garment was of skin, its lower half was slit into fringes. This allowed much greater freedom of movement, but the decorative effect was also felt and used. Of vegetable fibers the most frequently used was the inner bark of trees shredded and gathered on a cord. Grass, tule, ordinary cordage, and wrapped thongs are also reported.

As protection against rain and wind, both sexes donned a skin blanket. This was either thrown over the shoulders like a cape, or wrapped around the body, or passed over one arm and under the other and tied or secured in front. Sea otter furs made the most prized cloak of this type where they could be obtained. Land otter, wild cat, deer, and almost every other kind of fur was not disdained. The woven blanket of strips of rabbit fur or bird skin sometimes rendered service in this comnection, although also an article of bedding.

The moccasin which prevailed over central and northwestern California was an unsoled, single-piece, soft shoe, with one seam up the front and another up the heel. This is the Yurok, Hupa, and Miwok type. The front seam is puckered, but sometimes with neat effect. The heel seam is sometimes made by a thong drawn through. The Lassik knew a variant form, in which a single seam from the little toe to the outer ankle sufficed. The draw-string varied: the Miwok did without, the Lassik placed it in front of the ankle, the Yurok followed the curious device of having the thong, self-knotted inside, come out through the sole near its edge, and then lashing it over instep and heel back on itself. This is an arrangement that would have been distinctly unpractical on the side of wear had the moceasins been put on daily or for long journeys: Separate soles of rawhide are sometimes added, but old specimens are usually without, and the idea does not seem native. The Californian moceasin is rather higher than that of the Plains tribes, and appears not to have been worn with its ankle portion turned down. Trurneys, war, wood gathering, are the occasions mentioned for the donning of moccasins; as well as cold weather, when they were srinetims linnd with grass. They were not worn about the village or on ordinar? xirsions.

The Modoc and Klamat! momusn s. is part through Eastern modification. It appears to hav - bet whout stuff sole, but contains three pieces: the srie and moce proper, earing barely to the ankle; a U-shaped mist ahov foes, prolonger into a loose tongue above; and a strip aronut the ankles sewed to the edge of the main piece, and coming forward as far as the tmigue. The main piece has 
the two seams customary in California, except that the toe seam of course extends only to the bottom of the inset. The ankle piece can be worn turned down or up; the drawstring passes across the front of the tongue.

Southern California is a region of sandals ; but the desert Cahuilla wore a high moccasin for travel into the mountains. The hard sole curls over the thick but soft upper, and is sewed to it from the inside by an invisible stitch. The upper has its single seam at the back. The front is slit down to the top of the instep, and held together by a thong passed through the edges once or twice. The appearance of this moccasin is Southwestern, and its structure nearly on the plan of a civilized shoe. It reaches well up on the ealf.

Moccasins and leggings in an openwork twining of tule fibers were used in northeastern California and among the Clear lake Pomo as a device for holding a layer of soft grass against the foot.

The skin legging is rarer than the moceasin. It was made for special use, such as travel through the snow.

In southern California, the sandal of the Southwest begins to appear. In its most characteristic form it consists of yucea fiber, apparently folded around a looped frame or string. The Colorado river tribes have abandoned the use of this form of sandal if ever they possessed it. In recent years they have worn simple rawhide sandals ; but their very slender opportunities to hunt render it doubtful whether this is a type that antedates the introduction of horses and cattle among them. The Chemehuevi are said to have worn true moccasins. There is no clear report of any sandal north of Tehachapi.

The woman's basketry cap, a brimless cone or frustum, is generally considered a device intended to protect against the chafe of the pack strap. That this interpretation is correct is shown by the fact that in the south the cap is worn chiefly when a load is to be carried; whereas in the north, where custom demands the wearing of the cap at all ordinary times, it is oceasionally donned also by men when it becomes of service to them in the handling of a dip net which is steadied with the head. The women's cap, however, is not a generic Californian institution. In the greater part of the central area it is unknown. Its northern and southern forms are quite distinct. Their distribution shows them to be direct adjuncts of certain basketry techniques. The northern cap coincides with the Xerophyllum tenax. technique and is therefore always made in overlaid twining. The range of the southern cap appears to be icentical with that of baskets 
made on a foundation of Epicampes rigens grass and is thus a coiled product. There ean be no question that tribes following other basketry techniques possessed the ability to make eaps; but they did not do so. It is curic s that an object of evident utilitarian origin, more or less influenced oy fashion, should have its distribution limited according to the prc , alence of basketry techniques and materials.

Two minor varieties of the cap occur. Among the Chemehuevi the somewhat peaked, diagonally-twined cap of the Great Basin Shoshoneans was in use. From them it had spread in some measure to the typical southern California tribes as far as the Diegueño. This is likely to have been a comparatively recent invasion, since the two types are found side by side among the same people-a condition contrary to prevailing precedent.

The Modoc employ but little overlay twining, and most of their caps are wholly in their regular teehnique of simple twining with tule materials. The Modoc cap averages considerably larger and is more distinctly flat topped than that of the other northern Californians.

Inasmuch as woven caps and hats are worn all along the Pacific coast to Alaska and through a great part of the Plateau and Great Basin area, the two Californian types are but occurrences in a larger continuous area, and can therefore scarcely be interpreted as having originated quite independently. Rather is central California to be looked upon as a tract that once had and then lost the cap, or possibly always resisted its invasion.

The hair net worn by men clearly centers in the region of the Kuksu religion, but its distribution seems most accurately described as exelusive of that of the woman's cap. Thus the Kato probably used the net and not the cap, the adjacent Wailaki reversed the habit. There are a few overlappings, as among the Yokuts, who employed both objects. The head net is also reported for the Shasta of Shasta valley, but may have penetrated to them with the Kuksu elements carried into this region in recent years by the ghost dance. 


\section{HOUSES}

The houses of native California are difficult to classify except in summary fashion. The extreme forms are well differentiated, but are all connected by transitions. The frame house of the Yurok and Hupa is a definite type whose affinity with the larger plank house of the North Pacific coast is sufficiently evident. Southward and eastward from the Yurok this house becomes smaller and more rudely made. Bark begins to replace the split or hewn planks, and before long a conical form made wholly of bark slabs is attained. This in turn, if provided with a center post, need only be covered with earth to serve as the simple prototype of the large semi-subterranean house of the Sacramento valley. Again, the bark is often partly replaced by poles and sticks. If these are covered with thatch, we have a simple form of the conical brush house. This in turn also attains the rectangular form characteristic of the perfect form of plank house, but in other cases is made oval or round and domed, as among the Chumash. In this event it differs from the semi-subterranean house only in the lack of earth covering and its consequent lighter construction. A further transition is afforded by the fact that the earth house almost invariably has foliage of some kind as its topmost covering immediately below the earth surfacing. The brush house is often dug out a short distance. The Chumash threw the earth from the excavation up against the walls for a few feet. The earth covered house proper is only a little deeper and has the covering extending all the way over.

Neither shape, skeleton structure, nor materials, therefore, offer a satisfactory basis for the distinction of sharp types. A classification that would be of value would have to rest on minute analysis, preceded in many cases by more accurate information than is now available. Among numerous tribes the old types of houses have long since gone out of use. Among most of the remainder they have been at least partly modified, and the majority of early descriptions are too summary to be of great service.

Nor does a consideration of the distribution of house forms hold much present promise of fuller understanding. The earth covered house was made from the Modoc, Achomawi, and Yuki south to the Miwok; then again in the extreme part of southern California. The bark house is found chiefly among mountain tribes, but no very close correlation with topography appears. The well fashioned plank house 
is definitely to be associated with the northwestern culture. The earth lodge of the Sacramento valley region is evidently connected with the Kuksu religion on one side, since the southward limits of distribution of the two appear to coincide. Northward, however, this form of house extends considerably beyond the cult. The southern earth lodge probably has the center of its distribution among the Colorado river tribes. It appears to have penetrated somewhat farther west than the religious influences emanating from this district.

From the Chumash to the southern valley Yokuts, communal houses were in use. Yet the larger specimens of the earth lodges of the Sacramento valley district must also have sheltered more people than we reckon to a family; and the same is true of the thatched houses of the Pomo.

As regards affiliations outside of California, there is the same uncertainty. Are we to reckon the semi-subterranean house of interior British Columbia as one in type with the Navaho hogan simply because the two are roofed with earth; or is the hogan essentially of the type of the plains tepee by reason of its conical shape and tripod foundation? Until such broader problems are answered, it would scarcely be sound to attempt a definitive classification of the dwellings of aboriginal California.

The separate hut for the woman in her periodical illness seems to be a northern Californian institution. Information is irregular, but the groups who affirm that they formerly erected such structures are the Yurok, Karok, Hupa; probably the other northwestern tribes; the Shasta and Modoc; the northern Maidu; and apparently the Pomo. The Yuki and Sinkyone deny the practice, but their geographical situation renders unconfirmed negative statements somewhat doubtful. South of the Golden Gate, there is no clear reference to separate huts for women except among the Luiseño, and the Yokuts specifically state that they did not build them.

\section{THE SWEAT-HOUSE}

The sweat-house is a typical Californian institution if there is any; yet it was not in universal use. The Colorado river tribes lacked it or any substitute; and a want of reference to the structure among a series of Shonhonean desert tribes, such as the Chemehuevi and the eastern Mono, indicates that these must perhaps be joined to the agricultural Yumans in this respect; although an earth sweat-house is reported from the Panamint. The non-use of the sweat-house among 
the Yuma and Mohave appears to be of rather weighty historical significance, since on their eastern side the edifice was made by the nomadic tribes of the Southwest, and a related type-the kiva or estufa-is important among the Pueblos.

The Californian sweat-house is an institution of daily, not occasional, service. It serves a habit, not a medicinal treatment; it enters into ceremony indirectly rather than specifically as a means of purification. It is the assembly of the men, and often their sleeping quarters. It thus comes to fulfill many of the functions of a club; but is not to be construed as such, since ownership or kinship or friendship, not membership, determines admission; and there is no act of initiation.

In line with these characteristics, the California sweathouse was a structure, not a few boughs over, which a blanket was thrown before entry. It was earth-covered; except in the northwest, where an abundance of planks roofed a deep pit. In either case a substantial construction was requisite. A center post was often set up: logs and poles at any rate had to be employed.

Warmth was produced directly by fire, never by steam generated by heated stones. While the smoke was densest, the inmates lay close to the floor. Women were never admitted, except here and there on special ceremonial occasions, when sweating became a subsidiary feature or was wholly omitted.

In general, the sweat-house was somewhat smaller than the living house. This holds of the northwestern tribes, the Yokuts, and the groups of southern California. In the region of the Kuksu religion, the dance house or ceremonial assembly chamber-built much like the sweat-house elsewhere but on a far ampler scale-has come to be known as "sweat-house", among both Indians and whites. It is not likely that this large structure ever really replaced the true sweathouse in and about the Sacramento valley. The two may generally have existed side by side, as is known to have been the case among the Pomo and Patwin, but the smaller edifice have lost its proper identity in description under the unfortunate looseness of nomenclature; much as among tribes like the Yana, the Indians now speak of "sweat-houses" inhabited by families. Some careful because belated inquiries remain to be made to dispel the uncertainty in this matter. It would seem that in the Sacramento valley region there were three sizes of earth-covered structures: the large dance house, the moderately spaced living house, and the small sweat-house proper. 
In extreme northeastern California the Plains form of sweathouse has obtained a foothold: a small dome of willows covered with mats, large enough for a few men to sit up in, heated by steam. This is established for the Modoc, while less complete descriptions suggest the same for the Shasta, Achomawi, and Washo; but among at least some of these groups the steam sweat-house is of modern introduction.

It is notable that there is no indication of any fusion or hybridization of the Californian and the Eastern types of sweat-house even in the region where they border. This condition is typical of cultural phenomena in native America, and probably throughout the world, as soon as they are viewed distributionally rather than in their developmental sequence. Civilizations shade by endless transitions. Their elements wander randomly, as it seems, with little reference to the eircumstances of their origin. But analogous or logically equivalent elements exclude each other far more often than they intergrade.

\section{BOATS}

Native California used two types of boat-the wooden canoe and the tule balsa, a shaped raft of rushes. Their use tends to be exclusive without becoming fully so. Their distribution is determined by cultural more than by physiographic factors.

The northwestern canoe was employed on Humboldt bay and along the open, rocky coast to the north, but its shape as well as range indicate it to have been devised for river use. It was dug out of half a redwood log, was square ended, round bottomed, of heavy proportions, but nicely finished with recurved gunwales and carved-out seat. A similar if not identical boat was used on the southern Oregon coast beyond the range of the redwood tree. The southern limit is marked by Cape Mendocino and the navigable waters of Eel river. Inland, the Karok and Hupa regularly used canoes of Yurok manufacture, and occasional examples were sold as far upstream as the Shasta.

The southern California canoe was a seagoing vessel, indispensable to the Shoshonean and Chumash islanders of the Santa Barbara group, and considerably employed also by the mainlanders of the shore from Point Concepcion and probably San Luis Obispo as far south as San Diego. It was usually of lashed planks, either because solid timber for dugouts was scant, or because dexterity in woodworking rendered 
a carpentered construction less laborious. A dugout form seems also to have been known, and perhaps prevailed among the manually clumsier tribes toward San Diego. A double-bladed paddle was used. The southern California canoe was purely maritime. There were no navigable rivers, and on the few sheltered bays and lagoons the balsa was sufficient and generally employed. The size of this canoe was not great, the beam probably narrow, and the construction light; but the sea is normally calm in southern California and one side of the islands almost always sheltered.

A third type of canoe had a limited distribution in favorable localities in northern California, ranging about as far as overlay twining, and evidently formed part of the technological culture characteristic of this region. A historical community of origin with the northwestern redwood canoe is indubitable, but it is less clear whether the northeastern canoe represents the original type from which the northwestern developed as a specialization, or whether the latter is the result of coastal influences from the north, and the northeastern form a deteriorated marginal extension. This northeastern canoe was of pine or cedar or fir, burned and chopped out, narrow of beam, without definite shape. It was made by the Shasta, Modoc, Atsugewi, Achomawi, and northernmost Maidu.

The balsa or rush raft had a nearly universal distribution, so far as drainage conditions permitted ; the only groups that wholly rejected it in favor of the canoe being the Chumash and the northwestern tribes. It is reported from the Modoc, Achomawi, Northern Paiute, Wintun, Maidu, Pomo, Costanoans, Yokuts, Tübatulabal, Luisẹno, Diegueño, and Colorado river tribes. For river crossing, a bundle or group of bundles of tules sufficed. On large lakes and bays wellshaped vessels, with pointed and elevated prow and raised sides, were often navigated with paddles. The balsa does not appear to have been in use north of California, but it was known in Mexico, and probably has a continuous distribution, except for gaps due to negative environment, into South America.

The balsa was most often poled; but in the deep waters of San Francisco bay the Costanoans propelled it with the same doublebladed paddle that was used with the canoe of the coast and archipelago of southern California, whence the less skilful northerners may be assumed to have derived the implement. The double paddle is extremely rare in America; like the "Mediterranean" type of arrow release, it appears to have been recorded only from the eastern 
Eskimo. The Pomo of Clear lake used a single paddle with short broad blade. The canoe paddle of the northwestern tribes is long, narrow, and heavy, having to serve both as pole and as oar; that of the Klamath and Modoc, whose lake waters were currentless, is of more normal shape. Whether or not the southerners employed the onebladed paddle in addition to the double-ended one, does not seem to be known.

The occurrence of the double-bladed paddle militates against the supposition that the Chumash plank canoe might be of Oceanic origin. It would be strange if the boat-minus the outrigger-could be derived from the central Pacific, its paddle from the Arctic. Both look like loeal inventions.

Except for Drake's reference to canoes among the Coast Miwokperhaps to be understood as balsas-there is no evidence that any form of boat was in use on the ocean from the Golden Gate to Cape Mendocino. A few logs were occasionally lashed into a rude raft when seal or mussel rocks were to be visited.

A number of interior groups ferried goods, children, and perhaps even women across swollen streams in large baskets or-in the south - pots. Swimming men propelled and guarded the little vessels. This custom is established for the Yuki, Yokuts, and Mohave, and was no doubt participated in by other tribes.

\section{FISHING}

In fresh water and still bays, fish are more successfully taken by rude people with nets or weirs or poison than by line. Fish hooks are therefore employed only occasionally. This is the case in California. There was probably no group that was ignorant of the fish hook, but one hears little of its use. The one exception was on the southern coast, where deep water appears to have restricted the use of nets. The prevalent hook in this region was a single curved piece cut out of haliotis shell. Elsewhere the hook was in use chiefly for fishing in the larger lakes, and in the higher mountains where trout were taken. It consisted most commonly of a wooden shank with a pointed bone lashed backward on it at an angle of 45 degrees or less. Sometimes two such bones projected on opposite sides. The gorget, a straight bone sharpened on both ends and suspended from a string in its middle, is reported from the Modoc, but is likely to have had a wider distribution. 
The harpoon was probably known to every group in California whose territory contained sufficient bodies of water. The Colorado river tribes provide the only exception : the stream is too murky for the harpoon. The type of implement is everywhere substantially identieal. The shaft, being intended for thrusting and not throwing, is long and slender. The foreshaft is usually double, one prong being slightly longer than the other, presumably because the stroke is most commonly delivered at an angle to the bottom. The toggle heads are small, of bone and wood tightly wrapped with string and pitched. The socket is most frequently in or near the end. The string leaving the head at or near the middle, the socket end serves as a barb. This rather rude device is sufficient because the harpoon is rarely employed for game larger than a salmon. The lines are short and fastened to the spear.

A heavier harpoon which was perhaps hurled was used by the northwestern coast tribes for taking-sea lions. Only the heads have been preserved. These are of bone or antler and possess a true barb as well as socket.

A single example of a Chumash sealing harpoon has been preserved. This has a detachable foreshaft of wood, set in a socket of the main shaft, and tipped with a non-detachable flint blade and a bone barb that is lashed and asphalted on immediately behind the blade.

There is one record of the spear thrower: also a specimen from the Chumash. This is of wood and is remarkable for its excessively short, broad, and unwieldy shape. It is probably authentic, but its entire uniqueness renders caution necessary in drawing inferences from this solitary example.

The seine for surrounding fish, the stretched gill net, and the dip net were known to all the Californians, although many groups had occasion to use only certain varieties. The form and size of the dip net of course differed according as it was used in large or small streams, in the surf or in standing waters. The two commonest forms of frame were a semicircular hoop bisected by the handle, and two long diverging poles crossed and braced in the angle. A kite-shaped frame was sometimes employed for scooping. Nets without poles had floats of wood or tule stems. The sinkers were grooved or nicked stones, the commonest type of all being a flat beach pebble notched on opposite edges to prevent the string slipping. Perforated stones are 
known to have been used as net sinkers only in northwestern California and even there they occur by the side of the grooved variety. They are usually distinguishable without difficulty from the perforated stone of southern and central California which served as a digging stick weight, by the fact that their perforation is normally not in the middle. The northwesterners also availed themselves of naturally perforated stones.

Fish poison was fed into small streams and pools by a number of tribes: the Pomo, Yokuts, and Luiseño are specified, which indicates that the practice was widely spread. Buckeyes and soaproot (Chlorogalum) as well as other plants were employed.

\section{BOWs}

The bow was self, long, and narrow in the south, sinew-backed, somewhat shorter, thin, and broad in northern and central California. Of course light unbacked bows were used for small game and by boys everywhere. The material varied locally. In the northwest. the bow was of yew and shorter and flatter than anywhere else; the wood was pared down to little greater thickness than the sinew, the edge was sharp, and the grip much pinched. Good bows of course quickly went out of use before firearms, so that few examples have been preserved anywhere except low-grade modern pieces intended for birds and rabbits. But sinew backing is reported southward to the Yokuts and Panamint, so that the Tehachapi range may be set as the limit. The Yokuts name of the Kitanemuk meant "large bows." This group therefore is likely to have used the southern self bow. On the other hand, a specimen attributed to the Chumash is sinew-backed, thong-wound in the middle, and has a three-ply sinew cord. As the piece is narrower than the northern bows and the wood does not seem to be yew, the attribution is probably correct.

The arrow was normally two-pieced, its head most frequently of obsidian, which works finer and smaller as well as sharper than flint. The butt end of the point was frequently notched for a sinew lashing. The foreshaft was generally set into the main shaft. For small game shot at close range one-piece arrows frequently sufficed: the stone head was also omitted, or replaced by a blunted wooden point. Cane was used as main shaft wherever it was available, but nowhere exclusively. From the Yokuts south to the Yuma the typical fighting arrow was a simple wooden shaft without head, quantity rather than 
effectiveness of ammunition appearing the desideratum. The same tribes, however, often tipped their cane deer-arrows with stone.

The arrow release has been described for but three groups. None of these holds agrees, and two are virtually new for America. The Maidu release is the primary one, the Yahi a modification of the Mongolian, the Luiseño the pure Mediterranean, hitherto attributed in the new world only to the Eskimo. This remarkable variety in detail is characteristic of California.

The arrow was bent straight in a hole cut through a slab of wood, and polished with Equisetum or in two grooved pieces of sandstone in the north. The southern straightener and polisher is determined by the cane arrow: a transversely grooved rectangle of steatite set by the fire. This Southwestern form extends north at least to the Yokuts; the Maidu possessed it in somewhat aberrant form.

\section{TEXTILES}

Basketry is unquestionably the most developed art in California, so that it is of interest that the principle which chiefly emerges in connection with the art is that its growth has been in the form of what ethnologists are wont to name "complexes." That is to say, materials, processes, forms, and uses which abstractly considered bear no intrinsic relation to one another, or only a slight relation, are in fact bound up in a unit. A series of tribes employs the same forms, substances, and techniques; when a group is reached which abandons one of these factors, it abandons most or all of them, and follows a characteristically different art.

This is particularly clear of the basketry of northernmost California. At first sight this art seems to be distinguished chiefly by the outstanding fact that it knows no coiling processes. Its southern line of demarcation runs between the Sinkyone and Kato, the Wailaki and Yuki, through Wintun and Yana territory at points that have not been determined with certainty, and between the Achomawi (or more strictly the Atsugewi) and the Maidu. Northward it extends far into Oregon west of the Cascades. The Klamath and Modoc do not adhere to it, although their industry is a related one.

Further examination reveals a considerable number of other traits that are universally followed by the tribes in the region in question. Wicker and checker work, which have no connection with coiling, are also not made. Of the numerous varieties of twining, the plain weave 
is substantially the only one employed, with some use of subsidiary strengthening in narrow belts of three-strand twining. The diagonal twine is known, but practiced only sporadically. Decoration is wholly in overlay twining, each weft strand being faced with a colored one. The materials of this basketry are hazel shoots for warp, conifer roots for weft, and Xerophyllum, Adiantum, and alder-dyed Woodwardia for white, black, and red patterns respectively. All these plants appear to grow some distance south of the range of this basketry. At least in some places to the south they are undoubtedly sufficiently abuudant to serve as materials. The limit of distribution of the art can therefore not be ascribed to botanical causes. Similarly, there is no easily seen reason why people should stop wearing basketry caps and pounding acorns in a basketry hopper because their materials or technique have become different. That they do, evidences the strength of this particular complex.

In southern California a definite type of basket ware is adhered to with nearly equal rigidity. The typical technique here is coiling, normally on a foundation of straws of Epicampes grass. The sewing material is sumac or Juncus. Twined ware is subsidiary, is roughly done, and is made wholly in Juncus - a material that, used alone, forbids any considerable degree of finish. Here again the basketry cap and the mortar hopper appear but are limited toward the north by the range of the technique.

From southern California proper this basketry has penetrated to the southerly Yokuts and the adjacent Shoshonean tribes. Chumash ware also belongs to the same type, although it often substitutes Juncus for the Epicampes grass and sometimes uses willow. Both the Chumash and the Yokuts and Shoshoneans in and north of the Tehachapi mountains have developed one characteristic form not found in southern California proper: the shouldered basket with constricted neck. This is represented in the south by a simpler form, a small globular basket. The extreme development of the "bottleneck" type is found among the Yokuts, Kawaiisu, and Tübatulabal. The Chumash on the one side, and the willow-using Chemehuevi on the other, round the shoulders of these vessels so as to show a partial transition to the southern California prototype.

The Colorado river tribes slight basketry to a very unusual degree. They make a few rude trays and fish traps. The majority of their baskets they seem always to have acquired in trade from their neighbors. Their neglect of the art recalls its similar low condition among 
the Pueblos, but is even more pronounced. Pottery making and agriculture seem to be the influences most largely responsible.

Central California from the Yuki and Maidu to the Yokuts is an area in which coiling and twining occur side by side. There are probably more twined baskets made, but they are manufactured for rougher usage and more often undecorated. Show pieces are usually coiled. The characteristic technique is therefore perhaps coiling, but the two processes nearly balance. The materials are not so uniform as in the north or south. The most characteristic plant is perhaps the redbud, Cercis occidentalis, which furnishes the red and often the wbite surface of coiled vessels and is used in twining also. The most common techniques are coiling with triple foundation and plain twining. Diagonal twining is however more or less followed, and lattice twining, single-rod coiling, and wicker work all have at least a local distribution. Twining with overlay is never practiced. Forms are variable, but not to any notable extent. Oval baskets are made in the Pomo region, and occasionally elsewhere, but there is no shape of so pronounced a character as the southern Yokuts bottleneck.

A number of local basketry arts have grown in central California on this generic foundation. The most complicated of these is that of the Pomo and their immediate neighbors, who have developed feather-covering, lattice-twining, checker-work, single-rod coiling, the mortar hopper, and several other specializations. It may be added that the Pomo appear to be the only central Californian group that habitually make twined baskets with patterns.

Another definite center of development includes the Washo and in some measure the Miwok. Both of these groups practice single-rod coiling and have evolved a distinctive style of ornamentation characterized by a certain lightness of decorative touch. This ware, however, shades off to the south into Yokuts basketry with its southern California affiliations, and to the north into Maidu ware.

The latter in its pure form is readily distinguished from Miwok as well as Pomo basketry, but presents few positive peculiarities.

Costanoan and Salinan baskets perished so completely that no very definite idea of them can be formed. It is unlikely that any very marked local type prevailed in this region, and yet there are almost certain to have been some peculiarities.

The Yuki, wedged in between the Pomo and tribes that followed the northern California twining, make a coiled ware which with all its simplicity cannot be confounded with that of any other group in 
California; this in spite of the general lack of advancement which pervades their culture.

It thus appears that we may infer that a single style and type underlies the basketry of the whole of central California; that this has undergone numerous local diversifieations due only in part to the materials available, and extending on the other hand into its purely decorative aspeets; and that the most active and proficient of these loeal superstruetures was that for which the Pomo were responsible, their ereation, however, differing only in degree from those which resulted from analogous but less active impulses elsewhere. In central California, therefore, a basic basketry complex is less rigidly developed, or preserved, than in either the north or the south. The flora being substantially. uniform through eentral California, differences in the use of materials are in themselves significant of the incipient or superficial diversifications of the art.

The Modoe constitute a sub-type within the area of twining. They overlay chiefly when they use Xerophyllum or quills, it would seem, and the majority of their baskets, which are composed of tule fibers of several shades, are in plain twining. But the shapes and patterns of their ware have elearly been developed under the influences that guide the art of the overlaying tribes; and the cap and hopper oceur among them.

It is diffieult to decide whether the Modoe art is to be interpreted as a form of the primitive style on which the modern overlaying eomplex is based, or as a readaptation of the latter to a new and widely useful material. The question ean scarcely be answered without full consideration of the basketry of all Oregon.

Cloth is unknown in aboriginal California. Rush mats are twined like baskets or sewn. The nearest approach to a loom is a pair of upright sticks on which a long cord of rabbit fur is wound back and forth to be made into a blanket by the intertwining of a weft of the same material, or of two cords. The Maidu and southern Californians, and therefore probably other tribes also, made similar blankets of feather cords or strips of duck skin. The rabbit skin blanket has of course a wide distribution outside of California; that of bird skins may have been devised locally. 


\section{POTTERY}

The distribution of pottery in California reveals this art as surely due to Southwestern influences. It is practiced by the Yuma, Mohave, and other Colorado river tribes; sporadically by the Chemehuevi; by the Diegueño, Luiseño, Cupeño, Serrano, and Cahuilla; probably not by the Gabrielino; with the Juaneño doubtful. A second area, in which cruder pottery is made, lies to the north, apparently disconnected from the southern California one. In this district live the southern and perhaps central Yokuts, the Tübatulabal, and the Western Mono. This ware seems to be pieced with the fingers; it is irregular, undecorated, and the skill to construct vessels of any size was wanting. The southern Californians tempered with crushed rock, employed a clay that baked dull reddish, laid it on in thin spiral coils, and smoothed it between a wooden paddle and a pebble. They never corrugated, and no slipped ware has been found in the region; but there was some variety of forms-bowls, jars, pots, oval plates, short handled spoons, asymmetrical and multiple-mouthed jars, pipes-executed in a considerable range of sizes. Designs were solely in yellow ochre, and frequently omitted. They consisted chiefly of patterns of angular lines, with or without the corners filled in. Curves, solidly painted areas, and semi-realistic figures were rarely attempted. The ware was light, brittle, and porous.

The art during the last generation has been best preserved among the Mohave, and seems at all times to have attained greatest development on the Colorado river. But the coast tribes may have been substantial equals before they came under Caucasian influence, except that they decorated less. An affinity with ancient Pima and Seri ware is unmistakable; but it is far from attaining identity. There is no direct or specific resemblance to any present or ancient Pueblo pottery. This argues a local origination under outside influence, not an importation of the art as such; at any rate not from the true Pueblo area. Sonora is rather indicated as the source of stimulation. Potsherds indistinguishable from the modern ware occur in ancient sites on the Diegueño coast. Whether or not they extend to the earlier deposits remains to be ascertained; but they testify that the art is not an entirely recent one. Pottery was not established in California as a mere adjunct of agriculture, its distribution being considerably greater. 
Pottery, then, must be reckoned as historically in a class with the religious institutions of southern California: a local growth, due to an ultimate stimulus from the Southwest.

\section{MUSICAL INSTRUMENTS}

The rattle is of three kinds in the greater part of California: the split elap stick for daneing, the gravel-filled cocoon bunch for shamanistic practices, the bundle of deer hoofs for the adolescent girl. South of Tehachapi these are generally replaced by a single form, whose material varies between turtle shell and gourd according to region. The northwest does not use rattles except in the adolescence ceremony; in which some tribes, such as the Hupa and Sinkyone, employ a modification of the clap stick, the Karok, Tolowa, and others the more general deer hoofs. The latter implement is known as far south as the Luiseño but seems to be associated with hunting or mourning ceremonies at this end of the state. The clap stick penetrated to the Gabrielino.

The notehed scraper or musical rasp has been reported only from the Salinans.

California is a drumless region, except in the area of the Kuksu cult. There a foot drum, a segment of a large eylinder of wood, is set at the back of the dance house, and held very sacred. Various substitutes exist: the Yurok beat a board with a paddle, the Maidu strike or rub baskets, the Mohave do the same before a resounding jar. But these devices accompany gambling or shamans' or narrative songs: none of the substitutes replace dance drums.

Whistles of bone or cane are employed far more frequently in dances than the drum-by practically all tribes, in fact, although of course in quite different connections.

The bull-roarer has been reported from several scattered tribes. As might be expected, its use is religious, but its specific service is not well known and may have varied. To the Luiseño it was a summons. It was not used by the northwestern nations.

The only true musical instrument in our sense is the flute, an open, reedless tube, blown across the edge of one end. Almost always it has four holes, often more or less grouped in two pairs, and is innocent of any definite sèle. It is played for self-recreation and courtship. The Mohave alone know a flageolet. 
The musical or resonant bow, a sort of jew's harp, the only stringed instrument of California, has been recorded among the Pomo, Maidu, Yokuts, and Diegueño, and no doubt had a wider distribution. It was tapped as a restful amusement, and sometimes in converse with the spirits.

It is remarkable, although abundantly paralleled among other Indians, that the only two instruments capable of producing a melody

$\checkmark$ were not used ceremonially. The cause may be their imperfection. The dance was based on song, which an instrument of rhythm could enrich, but with which a mechanically but crudely produced melody would have clashed.

It is also a curious fact that the comparatively superior civilization of the northwestern tribes was the one that wholly lacked drum. bull-roarer, and musical bow and made minimal employ of rattles.

\section{MONEY}

Two forms of money prevailed in California, the dentalium shell, imported from the far north; and the clam shell disk bead. Among the strictly northwestern tribes dentalia were alone standard. In a belt stretching across the remainder of the northern end of the state, and limited very nearly, to the south, by the line that marks the end of the range of overlay twined basketry, dentalia and disks were used side by side.

Beyond, to the southern end of the state, dentalia were so sporadic as to be no longer reckoned as money, and the clam money was the medium of valuation. It had two sourees of supply. On Bodega bay, perhaps also at a few other points, the resident Coast Miwok and neighboring Pomo gathered the shell Saxidomus aratus or gracilis. From Morro bay near San Luis Obispo to San Diego there occurs another large clam, Tivela or Pachydesma crassatelloides. Both of these were broken, the pieces roughly shaped, bored, strung, and then rounded and polished on a sandstone slab. The disks were from a third of an inch to an inch in diameter, and from a quarter to a third of an inch thick, and varied in value according to size, thickness, polish, and age. The Pomo supplied the north; southern and central California used Pachydesma beads. The Southern Maidu are said to have had the latter, which fact, on account of their remoteness from the supply, may account for the higher value of the currency among them than with the Yokuts. But the Pomo Saxidomus bead is likely also to have reached the Maidu. 
From the Yokuts and Salinans south, money was measured on the circumference of the hand. The exact distance traversed by the string varied somewhat aceording to tribe; the value in our terms appears to have fluctuated locally to a greater degree. The Pomo, Wintum, and Maidu seem not to have known the hand scale. They measured their strings in the rough by stretching them out, and appear to have counted the beads when they wished accuracy.

Associated with the two elam moneys were two kinds of valuables, both in crlindrical form. The northern was of magnesite, obtained in or near southeastern Pomo territory. This was polished and on baking took on a tawny or reddish hue, often variegated. These stone crlinders traveled as far as the Yuki and the Miwok. From the south came similar but longer and slenderer pieces of shell, white to violet in color, made sometimes of the columella of univalves, sometimes out of the hinge of a large rock oyster or rock elam, probably Hinnites gigantcus. The bivalve cylinders took the finer grain and seem to have been preferred. Among the Chumash, such pieces must have been fairly common, to judge from finds in graves. To the inland Yokuts and Niwok they were excessively valuable. Both the magnesite and the shell cylinders were perforated longitudinally, and often constituted the center pieee of a fine string of beads; but, however displayed, they were too precious to be properly elassifiable as ornaments. At the same time their individual variability in size and quality. and consequently in value, was too great to allow them to be reckoned as ordinary money. They may be ranked on the whole with the obsidian blades of northwestern California, as an equivalent of precious stones among ourselves.

The small univalve Olivella biplicata and probably other species of the same genus were used nearly everywhere in the state. In the north, they were strung whole; in central and southern California, frequently broken up and rolled into thin, slightly eoneave disks, as by the Southwestern Indians of today. Neither form had much value. The olivella disks are far more eommon in graves than elam disks, as if a change of custom had taken place from the prehistoric to the historic period. But a more likely explanation is that the olivellas accompanied the corpse precisely beeause they were less valuable, the clam eurrency either being saved for inheritance, or, if offered, destroyed by fire in the great mourning anniversary.

Haliotis was much used in necklaces, ear ornaments, and the like, and among tribes remote from the sea commanded a considerable price ; but it was nowhere standardized into curreney. 


\section{TOBACCO}

Tobacco, of two or more species of Nicotiana, was smoked everywhere, but by the Yokuts, Tübatulabal, Kitanemuk, and Costanoans it was also mixed with shell lime and eaten.

The plant was grown by the northwestern groups such as the Yurok and Hupa, and apparently by the Wintun and Maidu. This limited agriculture, restricted to the people of a rather small area remote from tribes with farming customs, is curious. The Hupa and Yurok are afraid of wild tobacco as liable to have sprung from a grave; but it is as likely that the cultivation produced this unreasonable fear by rendering the use of the natural product unnecessary, as that the superstition was the impetus to the cultivation.

Tobacco was offered religiously by the Yurok, the Hupa, the Yahi, the Yokuts, and presumably by most or all other tribes; but exact data are lacking.

The pipe is found everywhere, and with insignificant exceptions is tubular. In the northwest, it averages about six inches long, and is of hard wood scraped somewhat concave in profile, the bowl lined with inset soapstone. In the region about the Pomo, the pipe is longer, the bowl end abruptly thickened to two or three inches, the stem slender. This bulb-ended pipe and the bulb-ended pestle have nearly the same distribution and may have influenced one another. In the Sierra Nevada, the pipe runs to only three or four inches, and tapers somewhat to the mouth end. The Chumash pipe has been preserved in its stone exemplars. These normally resemble the Sierra type, but are often longer, normally thicker, and more frequently contain a brief mouthpiece of bone. Ceremonial specimens are sometimes of obtuse angular shape. The pottery making tribes of the south use clay pipes most commonly. These are short, with shouldered bowl end. In all the region from the Yokuts south, in other words wherever the plant is available, a simple length of cane frequently replaces the worked pipe; and among all tribes shamans have all-stone pieces at times. The Modoc pipe is essentially Eastern: a stone head $\checkmark$ set on a wooden stem. The head is variable, as if it were a new and not yet established form : a tube, an L, intermediate forms, or a disk.

The Californians were light smokers, rarely passionate. They consumed smaller quantities of tobacco than most Eastern tribes and did not dilute it with bark. Smoking was of little formal social con- 
sequence, and indulged in chiefly at bedtime in the sweat-house. The available species of Nicotiana were pungent and powerful in physiological effect, and quickly produced dizziness and sleep.

\section{VARIOUS}

The ax and the stone celt are foreign to aboriginal California. The substitute is the wedge or chisel of antler-among the Chumash of whale's bone-driven by a stone. This maul is shaped only in extreme northern California.

The commonest string materials are the bark or outer fibers of - dogbane or Indian hemp, Apocynum cannabinum; and milkweed, Asclepias. From these, fine cords and heavy ropes are spun by hand. Nettle string is reported from two groups as distant as the Modoc and the Luise other tribes are likely to have used it also as a subsidiary material. In the northwest, from the Tolowa to the Coast Yuki, and inland at least to the Shasta, Indian hemp and milkweed are superseded by a small species of iris-I. macrosiphon-from each leaf of which two thin, tough, silky fibers are scraped out. The manufacture is tedious, but results in an unusually fine, hard, and even string. In the southern desert, yucea fibers yield a coarse stiff cordage, and the reed-Phragmites-is also said to be used. Barks of various kinds, mostly from unidentified species, are employed for wrappings and lashings by many tribes, and grapevine is a convenient tying material for large objects when special pliability is not required. Practically all Californian cordage, of whatever weight, was two-ply before Caucasian contact became influential.

The carrying net is essentially southern so far as California is concerned, but connects geographically as well as in type with a net used by the Shoshonean women of the Great Basin. It was in use among all the southern Californians except those of the Colorado river and possibly the Chemehuevi, and extended north among the Yokuts. The shape of the utensil is that of a small hammock of large mesh. One end terminates in a heavy cord, the other in a loop. A varying type occurs in an isolated region to the north among the Pomo and Yuki. Here the ends of the net are carried into a continuous head band. This arrangement does not permit of contraction or expansion to accommodate the load as in the south. The net has also been mentioned for the Costanoans, but its type there remains unknown. It is possible that these people served as transmitters of the idea from the 
south to the Pomo. A curious device is reported from the Maidu. The pack strap, when not of skin, is braided or more probably woven. Through its larger central portion the warp threads run free without weft. This arrangement allows them to be spread out and to enfold a small or light load somewhat in the fashion of a net.

The carrying frame of the Southwest has no analogy in California except on the Colorado river. Here two looped sticks are crossed and their four lengths connected with light cordage. Except for the disparity between the frame and the shell of the covering, this type would pass as a basketry form, and at bottom it appears to be such. The ordinary openwork conical carrying basket of central and northern California is occasionally strengthened by the lashing in of four heavier rods. In the northeastern corner of the state, where exterior influences from eastern cultures are recognizable, the carrier is sometimes of hide fastened to a frame of four sticks.

The storage of acorns or corresponding food supplies is provided for in three ways in California. All the southern tribes construct a large receptacle of twigs irregularly interlaced like a bird's nest. This is sometimes made with a bottom, sometimes set on a bed of twigs and covered in the same way. The more arid the climate, the less does construction matter. Mountain tribes make the receptacle with bottom and lid and small mouth. In the open desert the chief function of the granary is to hold the food together and it becomes little else than a short section of hollow cylinder. Nowhere is there any recognizable technique. The diameter is from two to six feet. The setting is always outdoors, sometimes on a platform, often on bare rocks, and occasionally on the ground. The Chumash did not use this type of receptacle.

In central California a cache or granary is used which can also not be described as a true basket. It differs from the southern form in usually being smaller in diameter but higher, in being constructed of finer and softer materials, and in depending more or less directly in its structure on a series of posts which at the same time elevate it from the ground. This is the granary of the tribes in the Sierra Nevada, used by the Wintun, Maidu, Miwok, and Yokuts, and in somewhat modified form-a mat of sticks covered with thatch-by the Western or mountain Mono. It has penetrated also to those of the Pomo of Lake county who are in direct communication with the Wintun. 
In the remainder of California, both north and south, large baskets-their type of course determined by the prevailing style of basketry-are set indoors or perhaps occasionally in caves or rock recesses.

The flat spoon or paddle for stirring gruel is widely spread, but far from universal. It has been found among all the northwestern tribes, the Aehomawi, Shasta, Pomo, Wappo, Northern Miwok, Washo, and Diegueño. 'The Yokuts and Sonthern Miwok, at times the Washo, use instead a looped stick, which is also convenient for handling hot cooking stones. The Colorado river tribes, who stew more civilized messes of eorn, beans, or fish in pots, tie three rods together for a stirrer. The Maidu alone are said to have done without an implement.

\section{SOCIETY \\ POLITICAL ORGANIZATION}

Tribes did not exist in California in the sense in which the word is properly applicable to the greater part of the North American continent. When the term is used it must therefore be understood as synonymous with "ethnic group" rather than as denoting political unity.

The marginal Mohave and the Yuma are the only Californian groups comparable to what are generally understood as "tribes" in the central and eastern United States : namely, a fairly coherent body of from five hundred to five thousand souls-usually averaging not far from two thousand; speaking in almost all cases a distinctive dialect or at least sub-dialect; with a political organization of the loosest, perhaps; but nevertheless possessed of a considerable sentiment of solidarity as against all other bodies, sufficient ordinarily to lead them to act as a unit. The uniquely enterprising military spirit displayed by the Yuma and Mohave is undoubtedly connected with this sense of cohesion.

The extreme of political anarehy is found in the northwest, where there was scarcely a tendency to group villages into higher units, and where even a village was not conceived as an assential unit. In practice a northwestern village was likely to act as a body, but it did so either because its inhabitants were kinsmen, or because it contained a man of sufficient wealth to have established personal relations of 
obligation between himself and individual fellow-townsmen not related to him in blood. The Yurok, Karok, and Hupa, and probably several of the adjacent groups, simply did not recognize any organization which transcended individuals and kin groups.

In north central California the rudiments of a tribal organization are discernible among the Pomo, Yuki, and Maidu and may be assumed to have prevailed among most other groups. A tribe in this region was a small body, evidently including on the average not much more than a hundred souls. It did not possess distinctive speech, a number of such tribes being normally included in the range of a single dialect. Each was obviously in substance a "village community," although the term "village" in this comnection must be understood as implying a tract of land rather than a settlement as such. In most cases the population of the little tribe was divided between several settlements, each presumably consisting of a few households more or less intimately connected by blood; but there was also a site which was regarded as the principal one inhabited. Subsidiary settlements were frequently abandoned, reoccupied, or newly founded. The principal village was maintained more permanently. The limits of the territory of the group were well defined, comprising in most cases a natural drainage area. A chief was recognized for the tribe. There is some indication that his elevation may often have been subject to popular consent, although hereditary tendencies are likely to have been rather more influential in most cases. The minor settlements or groups of kinsmen had each their lesser chief or head-man. There was no proper name for the tribe. It was designated either by the name of its principal settlement or by that of its chief. Among foreigners these little groups sometimes bore names which were used much like true tribal names; but on an analysis these almost invariably prove to mean only "people of such and such a place or district." This type of organization is likely to have prevailed as far south as the Miwok in the interior and the Costanoans or Salinans on the coast, and northward to the Achomawi and possibly the Modoc.

The Yokuts, and apparently they alone, attained a nearer approach to a full tribal system. Their tribes were larger, ranging from a hundred and fifty to four hundred or five hundred members; possessed names which usually did not refer to localities; and spoke distinctive dialects, although these were often only slightly divergent from the neighboring tongues. The territory of each tribe was larger than in the Maidu-Pomo region, and a principal permanent village looms with prominence only in some cases. 
The Shoshoneans of Nevada, and with them those of the eastern desert fringe of California, possessed an organization which appears to be somewhat akin to that of the Yokuts. They were divided into groups of about the same size as the Yokuts, each without a definite metropolis, rather shifting within its range, and headed by a chief possessing considerable influence. The groups were almost throughout named after a characteristic diet, thus "fish eaters" or "mountainsheep eaters." It is not known how far each of these tribes possessed a unique dialect: if they did, their speech distinctness was in most cases minimal. Owing to the open and poorly productive nature of the country, the territory of each of these groups of the Shoshonean Great Basin was considerably more extensive than in the Yokuts habitat.

Political conditions in southern California are very obscure, but are likely to have been generally similar to those of north central California. Among the Chumash, towns of some size were inhabited century after century, and these undoubtedly were the centers if not the bases of political groups.

The Mohave and other Yuman tribes of the Colorado valley waged war as tribal units. Their settlements were small, shifting, apparently determined in the main by the location of their fields, and enter little into their own descriptions of their life. It is clear that the Mohave's sense of attachment was primarily to his people as a body, and secondarily to his country as a whole. The Californian Indian, with the partial exception of the Yokuts, always gives the impression of being attached first of all to a spot, or at most a few miles of stream or valley, and to his blood kindred or a small group of lifelong associates and intimates.

It should be added that the subject of political organization is perhaps the topic in most urgent need of investigation in the whole field of California ethnology.

\section{THE CHIEF}

Chieftainship is still wrapped in much the same obscurity and vagueness as political bodies. There were no doubt hereditary chiefs in many parts of California. But it is difficult to determine how far inheritance was the formally instituted avenue to office, or was only actually operative in the majority of instances. In general it seems that chieftainship was more definitely hereditary in the southern half or two-thirds of the state than in the north central area. Wealth was a factor of 'some consequence in relation to chieftainship every- 
where, but its influence seems also to have varied aceording to locality. The northwestern tribes had hereditarily rich men of great influence, but no chiefs. Being without politieal organization, they eould not well have had the latter.

The degree of authority of the ehief is very difficult to estimate. This is a matter which can not be judged accurately from the accounts of relations between native groups and intruders belonging to a more highly civilized alien race. To understand the situation between the chief and his followers in the routine of daily life, it is neeessary to have at command a more intimate knowledge of this life before its disturbance by Caucasian culture than is available for most Californian groups. It does seem that the authority of the chief was considerable everywhere as far north as the Miwok, and by no means negligible beyond; while in the northwest the social effect of wealth was so great as to obtain for the rich a distinctly eommanding position.

$\rightarrow$ Among certain of the Shoshoneans of southern California the chief, the assistant or religious chief, and their wives or children, were all known by titles; which fact argues that a fairly great deference was accorded them. Their authority probably did not lag much behind. Both the Juaneño and the Chumash are said to have gone to war to avenge slights put upon their chiefs. The director of rituals as an assistant to the head chief is a southern California institution. Somewhat similar is the central Yokuts practice of having two chiefs for each tribe, one to represent each exogamous moiety. The chief had speakers, messengers, or similar henchmen with named offices, among the Coast Miwok, the interior Miwok, the Yokuts, the Juaneño, and no doubt among other groups.

The chief was everywhere distinctly a civil official. If he commanded also in battle, it seems to have been only through the accident of being a distinguished warrior as well. The usual war leader was merely that individual in the group who was able to inspire confidence through having displayed courage, skill, and enterprise in combat. It is only natural that his voice should have carried weight even in time of peace; but he seems not to have been regarded as holding an office. This distinction between the chief and the military leader appears to apply even to the Yuma and Mohave, among whom bravery was the supreme virtue.

There were no hereditary priests in California. A religious function often passed from father to son or brother's son, but the successor took his place because his kinship had caused him to acquire the necessary knowledge, not in virtue of his descent as such. At that 
there was hardly a recognized class of priests. The old man who knew most held the direction of ceremonies; and in the Kuksu region a man became clown, or meki, or kuksu, or some other specific impersonator, rather than a priest as such.

The shaman of course was never an official in the true sense of the word. inasmuch as his power was necessarily of individual acquisition and varied directly according to his supernatural potency, or, as we should call it, his gifts of personality.

SOCIAL STRATIFICATION

Social classes of different level are hardly likely to develop markedly in so primitive a society as that of California. It is therefore highly distinctive of the northwestern area that the social stratification which forms so important an element in the culture of the North Pacific coast, appears among these people with undiminished vigor. The heraldic and symbolic devices of the more advanced tribes a thousand miles to the north are lacking among the Yurok: the consciousness of the different value of a rich and a poor man is as keen among them as with the Kwakiutl or the Haida.

The northwest is also the only part of California that knew slavery. This institution rested upon the economic basis of debt.

Wealth was by no means a negligible factor in the remainder of California, but it clearly did not possess the same influence as in the northwest. There seems to have bcen an effort to regulate matters so that the chief, through the possession of several wives, or through contributions, was in a position to conduct himself with liberality, especially toward strangers and in time of need. On the whole he was wealthy because he was chief rather than the reverse. Among the Colorado river tribes a thoroughly democratic spirit prevailed as regards property, and there was a good deal of the Plains sentiment that it behooved a true man to be contemptuous of material possessions.

\section{EXOGAMY AND TOTEMISM}

California was long regarded as a region lacking clans, group totems, or other exogamous social units. The Colorado river tribes were indeed known to be divided into clans, and the Miwok into moieties, both carrying certain rather indirect totemic associations. But these seemed to be isolated exceptions. More recent information, however, due mainly to the investigations of $\mathrm{E}$. W. Gifford, shows that some form of gentile organization was prevalent among nearly all 
groups from the Miwok south to the Yuma; and the principal types which this organization assumes have become clear at least in outline.

In brief the situation is this. Almost everywhere within the area in question, the units are exogamous. Nearly always they are totemic. Descent is invariably patrilinear. In the extreme south or southeast the division of society is on the basis of multiple clans; in the San Joaquin valley of moieties; between, that is, roughly in the region of the northern part of southern California, there are clans and moieties. Toward the head of the San Joaquin valley there is a tract over which clans, moieties, and totems are all lacking. This tongue of clanless area may represent intrusive or conservative influence from the desert Shoshoneans on the east. It very likely did not wholly sever the totemic social organizations of central and southern California, for there is no definite information available on the most southwesterly body of Yokuts, the Chumash, the Kitanemuk, or the Gabrielino, and if these groups possessed moieties, clans, or totems, they would connect the two areas into a continuous unit.

It is hardly possible to doubt that the totemic clan or moiety system of California stands in a positive historic relation to that of the Southwest. The fact of its being a patrilinear system, whereas the southwestern Indians reckon descent in the female line, indicates only that the connection is ancient and indirect. Both the chief other North American regions in which totemic clans or moieties prevail, the North Pacific coast and the eastern side of the continent, are divided into patrilinear and matrilinear sub-areas. The continental distribution is such that it would be more than hazardous to assume the patrilinear institutions of the North Pacific, the East, and the Southwest-California area to have been derived from a common source, and the matrilinear institutions of the same three regions from a second origin. It is as clear as such matters can be that a system of gentile organization developed around three centers-whether these were thoroughly independent of one another or were originally related is a question that need not be considered here-and that within each area, with the growth and diversification of the institution, paternal and maternal reckoning grew up side by side or one after the other. In other words, the impulse toward the division of society on the basis of exogamous hereditary groups is the older. The predominance accorded to one sex or the other in the reckoning of descent is a direction subsequently assumed. Such being the indicated course of continental development, we need be under no hesitation in linking 
the totemic exogamy of California with that of the Southwest, in spite of its decisive patrilinear character.

As to the age of the institution in the two regions, there can be little doubt that as in most matters probable precedence should be given to the Southwest on the ground of the generally greater complexity and development of its culture. It is only necessary to guard against the hasty inference that, because the connection is almost certain and the radiation from New Mexico and Arizona into California probable, this movement has been a recent one whose course can still be traced by the present location of this or that particular tribe.

The clans of the Colorado river tribes are fairly numerous, a dozen or more for each group. They have no names as such, but are each characterized by the use of a single name borne by all the women of a clan. These women's names can usually not be analyzed, but are understood by the Indians as denotive of an animal or object which is clearly the totem of the clan. This system is common without material modification to all the Yumans of the river, but the totemic references vary considerably, and the women's names even more. The latter must have fluctuated with considerable readiness, since only a small proportion of the total number known are common even to two tribes.

With the Diegueño and Luiseño the system loses many of its characteristics. Totemism, direct or indirect, is wholly lacking. The groups are numerous and small. Their names when translatable are mostly those of localities, or have reference to a locality. The native theory is clearly that each clan is a local kin group. How far this was actually the case, is very difficult to determine positively, since mission residence, and among even the remoter sections of these groups a century or more of Caucasian contact, have rather disintegrated the native life.

With the Cupeño, Cahuilla, and Serrano, the institution is reinvigorated. The local groups persist as among the Luiseño and Diegueño and bear similar names. They are, however, united into two great moieties-named after the coyote and wild cat-which are thus totemic, and which are also the essential units determining exogamy. The elans are numerous, small, and probably consist in the main of actual or even traceable blood kinsmen related in the male line.

From here on northward follows the gap in our knowledge. It is however certain that the Shoshonean Kawaiisu and Tiibatulabal, and 
the southern Yokuts such as the Yaudanchi and Yauelmani, were at least substantially free from the influence of any exogamous system.

When this negative or doubtful zone has been passed through, we find ourselves well in the San Joaquin valley. Here, among the central Yokuts, according to some slender indications among the Salinans, probably among the northern Yokuts, and among all the Sierra Miwok, clans have wholly disappeared. The exogamous moiety however remains, and its totemic aspects are rather more developed than in the south. The Miwok carry the totemic scheme farthest, dividing the universe as it were into totemic halves, so that all its natural contents are potential totems of one or the other moiety. Among the other groups of this region the totemism is generally restricted to a limited number of birds or animals. Moieties are variously designated as land and water, downstream and upstream, bluejay and coyote, bull-frog and coyote, or bear and deer. The totem is spoken of as the " $\operatorname{dog}$," that is domestic animal or pet, of each individual. Among the Miwok the personal name refers to an animal or object of the individual's moiety, but the totem itself is hardly ever expressed in the name, the reference being by some implication which can hardly be intelligible to those who do not know the individual and his moiety.

The Western Mono, at least in the northern part of their range, have come under the influence of the Miwok-Yokuts system, but this has assumed a somewhat aberrant shape among them. They subdivide each moiety into two groups which might be called clans except for the fact that they are not exogamous. The names of these groups have not yielded to certain translation. The Mono seem to identify them with localities.

Matrilinear descent has once been reported for a single Yokuts tribe, the Gashowu, but is so directly at variance with all that is known of the institutions of the region, as to be almost certainly an error of observation. On the other hand, there are more positive indications, mainly in kinship designations and the inheritance of chieftainship, of a reckoning in the female line among some of the Pomo and Wappo; and these are the more credible because the Pomo lie outside of the exogamic and totemic area of California. The evidence pointing to Pomo matrilineate is however slight, and it is clear that the institution was at most a sort of suggestion, an undeveloped beginning or last vestige, and not a practice of much consequence. 
This inference is strengthened by the fact that the several Pomo and Wappo divisions eonfliet in their usages on the points involved.

Totemic taboos are not known to have been strongly developed in California. Among most groups the totem seems to have been killed and eaten without further thought. Belief in descent from the totem is also weak or absent, except for some introduction of the moiety totems into the cosmogony of the Shoshoneans of the south.

The exogamic groups of California have rather few religious functions. The Colorado river elans seem to have no eonnection with ritual. The clans of some of the Shoshoneans-Luiseño, Cupeño, possibly Cahuilla-tended to be the bodies that conducted ceremonies, the instruments for ritual execution; although the rites were nearly identical, not peculiar to each clan. It appears also that these ritually functioning groups or "parties" often included several elans, and always admitted individuals who had become disgruntled with their hereditary groups. It is thus likely that these religious associations really erystallized around chiefs rather than on a clan basis. Indeed, the word for such a group is merely the word for chief. Among other groups of the south, such as the Serrano, the moieties, or their clan representatives in a given locality, appear to have been charged with religious privileges and duties. But the situation remains in need of more intimate elucidation. In the San Joaquin valley, the moieties assumed eeremonial obligations, usually reciprocal, and evidently in the main in connection with the mourning anniversary; but $/$ these arrangements faded out toward the north, among the Miwok.

\section{MARRIAGE}

Marriage is by purchase almost everywhere in California, the groups east of the Sierra and those on the Colorado river providing the only exceptions. Among the latter there is searcely a formality observed. A man and a woman go to live together and the marriage is recognized as long as the union endures. While some form of bridepurchase is in vogue over the remainder of the state, its import is very different according to locality. The northwestern tribes make of it a definite, commercial, negotiated transaction, the absence of which prior to living together constitutes a serious injury to the family of the girl, whereas a liberal payment enhances the status of both bride and groom and their children. In the sonthern half of the state, and among the mountaineers of the north, payment has little more significance than a customary observance. It might be described as an 
affair of manners rather than morals. Formal negotiations are not always carried on, and in some instances the young man shows his intentions and is accepted merely on the strength of some presents of game or the rendering of an ill-defined period of service before or after the union. Even within comparatively restricted regions there is considerable difference in this respect between wealthy valley dwellers and poor highlanders: the northern Maidu furnish an interesting case in point.

So far as known the levirate or marriage of the widow by her dead husband's brother was the custom of all Californians except those on the Colorado. The same may be said of the "sororate" or "glorate," the widower's marriage to his dead wife's sister, or in cases of polygamy to two sisters or to mother and daughter. On account of this almost universal occurrence, these customs may be looked upon as basic and ancient institutions. The uniformity of their prevalence in contrast to the many intergrading forms assumed by the marriage act, and in contrast also to the differences as regards exogamy, renders it highly probable that if an attempt be made to bring the levirate and sororate into relation with these other institutions, the levirate and sororate must be regarded as antecedent-as established practices to which marriage, exogamy, and descent conformed.

\section{VARIOUS SOCIAL HABITS}

A rigid custom prescribes that the widow crop or singe off her hair and cover the stubble as well as her face with pitch, throughout a great part of central California. This defacement is left on until the next mourning anniversary or for a year or sometimes longer. The groups that are known to follow this practice are the Achomawi, Shasta, Maidu, Wintun, Kato, Pomo, and Miwok; also the Chukchansi, that is the northern hill Yokuts. Among the Southern Yokuts the widow merely does not wash her face during the period in which she abstains from eating meat. Beyond the Yokuts, there is no reference to the custom; nor is it known from any northwestern people.

A mourning necklace is northern. The northwestern tribes braid a necklace which is worn for a year or longer after the death of a near relative or spouse. The Achomawi and Northeastern Maidu, perhaps other groups also, have their widows put on a necklace of lumps of pitch. 
A belt made of the hair cut from her head was worn by the widow among the Shastan tribes, that is the Shasta, Achomawi, and Atsugewi. In southern California, belts and hair ties and other ornaments of human hair reappear, but do not have so definite a reference to mourning.

The eouvade was praetieed by nearly all Californians, but not in its "elassic" form of the father alone observing restrictions and pretending to lie in. The usual custom was for both parents to be affected equally and for the same period. They observed food restraints and worked and traveled as little as possible in order to benefit their child; they did not ward illness from the infant by shamming it themselves. The custom might well be deseribed as a semi-couvade. It has been reported among the Aehomawi, Maidu, Yuki, Pomo, Yokuts, Juaneño, and Diegueño. Only the Yurok, Hupa, Shasta, and with them presumably the Karok and a few other northwestern tribes, are known not to have followed the practice. Here too there are certain restrictions on both parents; but those of the father are much the lighter and briefer.

Fear toward twins is known to have been felt by the Yurok, Achomawi, and Northwestern Maidu of the hills. It is likely to have prevailed more widely, but these instances suggest that the most acute development of the sentiment may have been localized in northern California.

The child's umbilical cord was saved, earefully disposed of, or specially treated. The Diegueño, Luiseño, Juaneño, and Chukchansi Yokuts buried it. The Tachi Yokuts tied it on the child's abdomen. The Hupa and Yurok kept it for a year or two, then deposited it in a split tree.

\section{KINSHIP TABOOS}

The taboo which forbids parents-in-law and children-in-law to look each other in the face or speak or communicate, was a central Californian custom. It is recorded for the Kato, Pomo, Maidu, Miwok, Yokuts, and Western Mono; with whom at least the southerly Wintun must probably be included. The Yuki, perhaps the Yana, the Eastern Mono, the Tiibatulabal, and the Kawaiisu seem not to have adhered to the practice, whose distribution is therefore recognizable as holding over a continuous and rather regular area whose core is the Sacramento-San .Joaquin valley. There is no mention of 
the habit in regard to any northwestern or southern tribe. Actually, the mother-in-law is alone specified in some instances, but these may be cases of loose or incomplete record. Accuracy also necessitates the statement that among the Kato and Pomo the custom has not been reported directly, but it is known that they address a parent-in-law in the plural-a device which the Miwok and Western Mono make use of as an allowable circumvention of the taboo when there is the requisite occasion. The Kato and Pomo were shy toward their parents-in-law, but much less scrupulous about rigidly avoiding all communication with them than the Northwestern Maidu.

It may be added that among the Yana and the Western Mono, two far separated and umrelated peoples, brother and sister used plural address. For the Yana it is stated that a certain degree of avoidance was also observed. This custom can be looked for with some likelihood among the intervening nations; but to predict it would be rash. There are many purely local developments in Californian culture: witness the sex diversity of speech among the Yana.

As in other parts of America, no reason for the custom can be obtained from the natives. It is a way they have, they answer; or they would be ashamed to do otherwise. That they feel positive disgrace at speaking brusquely to a parent-in-law is certain; but this sentiment can no more be accounted the direct cause of the origin of the custom than a sense of shame can by itself have produced the manifold varieties of dress current among mankind. It need not be doubted that a sense of delicacy with reference to sexual relations lies at the root of the habit. But to imagine that a native might really be able to explain the ultimate source of any of his institutions or manners, is of course unreasonable.

\section{DISPOSAL OF THE DEAD}

The manner of disposing of the dead varied greatly according to region in California. The areas in which cremation was practiced seem to aggregate somewhat larger than those in which burial was the custom, but the balance is nearly even, and the distribution quite irregular (map 2). Roughly, five areas can be distinguished.

The southern Californian area burned its dead. 


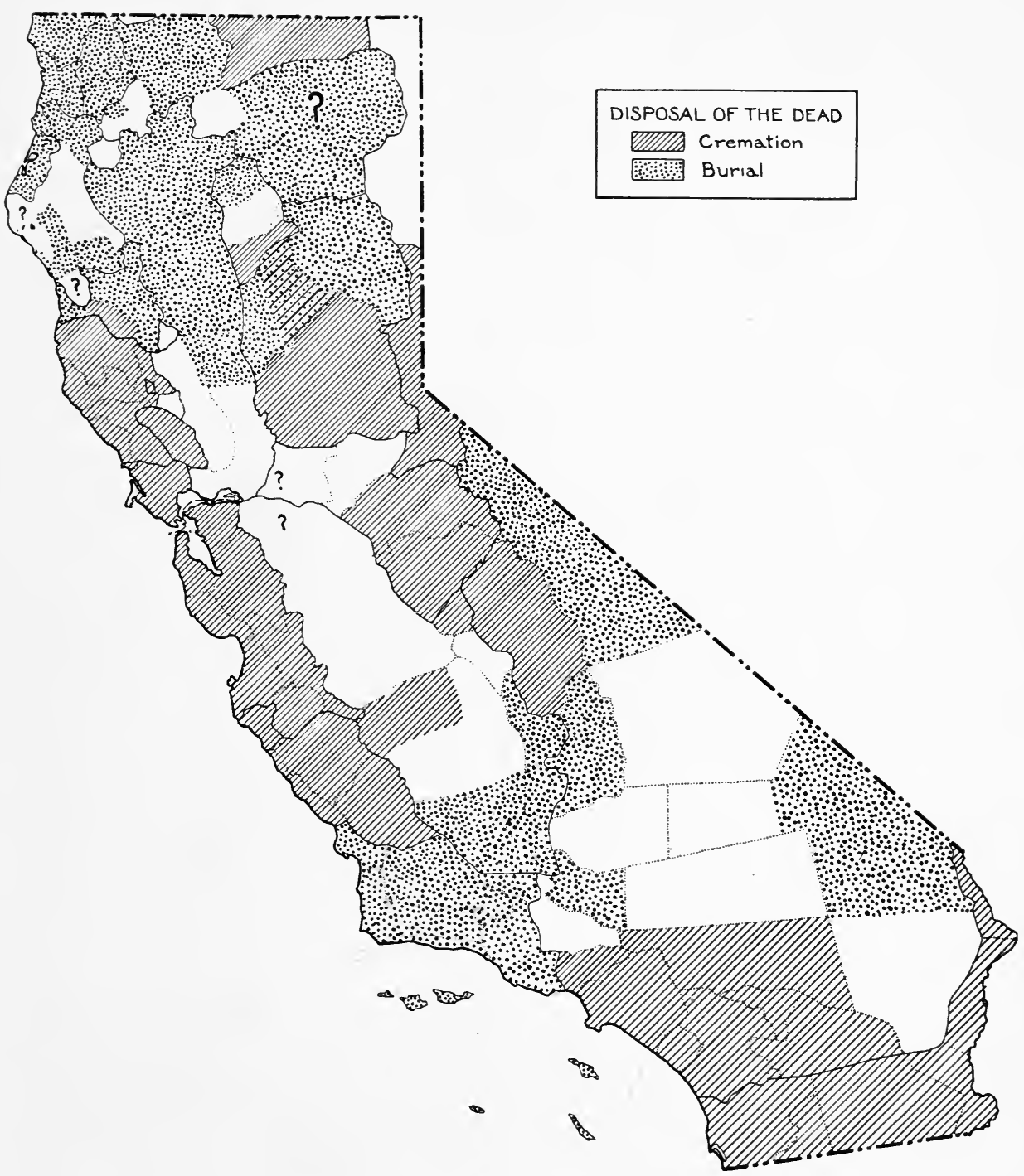

Map 2 
Interment was the rule over a tract which seems to extend from the Great Basin across the southern Sierras to the Chumash and Santa Barbara islands. This includes the Chemehuevi, the Eastern Mono, the Tübatulabal, the Southern Yokuts, the Chumash, and perhaps a few of the adjacent minor Shoshonean groups.

A second region of cremation follows. This consists of the entire central Sierra Nevada, the San Joaquin valley except at its head, the lower Sacramento valley, and the coast region for about the same distance. Roughly, the range is from the Salinans and Central Yokuts to the Pomo and Southern Maidu.

A second area of burial takes in all of the tribes under the influence of the northwestern culture, and in addition to them the Yuki, at least the majority of the Wintun, and most of the northern Maidu.

The Modoc in the northeastern corner of the state again cremated. For the adjoining Achomawi the evidence conflicts. It is possible that this northern region was connected with the central area of cremation through the Yahi and Northwestern Maidu of the foothills.

It seems impossible to establish any correlation between custom and environment in this matter. Treeless and timbered regions both cremated and in other cases interred.

It does appear that the southern and central culture areas can be described as regions of prevailing cremation, the northwestern culture and the desert as areas of burial. The practice of each of the two interring regions has to some extent penetrated the adjacent parts of the central area. Interment however extends farther beyond the outer limits of the northwestern culture than almost all other institutions or elements which are definitely characteristic of the northwest, basketry and dentalia, for instance. Furthermore, there is the curious assemblage of burying peoples from the Eastern Mono to the Santa Barbara islands, which can scarcely correspond to any primary cultural stratum.

\section{WARV}

Warfare throughout California was carried on only for revenge, never for plunder or from a desire of distinction. The Mohave and Yuma must indeed be excepted from this statement, but their attitude is entirely unique. Probably the cause that most commonly originated feuds was the belief that a death had been eaused by witcheraft. No doubt theft and disputes of various sorts also contributed. Once ill feeling was established, it was likely to continue for long periods. 
Even a reconeiliation and formal peace must generally have left lurking suspicions which the natives' theory of disease was likely at any moment to fan into fresh aceusation and a renewal of hostilities.

Torture has been reported as having been practiced by several tribes, such as the Maidu and the Gabrielino. It appears to have been considered merely a preliminary to the execution of eaptives, which was the victors' main purpose. As a rule, men who could be seized in warfare were killed and decapitated on the spot. Women and children were also slaughtered more frequently than enslaved. There is no record of any attempt to hold men as prisoners.

Sealps were taken in the greater part of California, brought home in triumph, and celebrated over, usually by a dance around a pole. Women as well as men generally participated. Some tribes made the dance indoors, other's outside. There was no great formality about this scalp dance of victory. It may often have been celebrated with great abandon, but its ritual was loose and simple. The Mohave and Yuma alone show some organization of the ceremony, coupled with a considerable manifestation of dread of the scalps themselves-a Southwestern trait.

It is rather difficult to decide how far the scalp taken was literally such and how far it was the entire head. A fallen foe that could be operated upon in safety and leisure was almost always decapitated, and his head brought home. Sometimes it is said that this head was danced with. In other localities it was skinned at the first opportunity and the sealp alone used in the dance. The scalp, however, was always a larger object than we are accustomed to think with the habits of eastern tribes in mind. The skin taken extended to the eyes and nose and included the ears. There is no evidence of an endeavor to preserve scalps as permanent trophies to the eredit of individuals; nor of a feeling that anything was lost by a failure to secure scalps, other than that an occasion for a pleasant celebration might be missed thereby.

It is signficant that it remains doubtful whether the Yokuts, the valley Maidu, and the Pomo took sealps or performed a sealp dance. If they did so, it was clearly with less zest than most of their neighbors. All of the tribes in question are peoples of lowland habitat, considerable wealth, and comparative specialization of eulture.

In the northwestern area no scalps were taken, and the victory dance was replaced by one of incitement before battle. In this dance the fully armed warriors stood abreast, with one or more of their 
number moving before them. With the Yurok and Hupa, and perhaps some of their immediate neighbors also, this dance was particularly made when two hostile parties gathered for a settlement of a feud; and, as might be expected, as often as not resulted in a new fight instead of the desired peace. The northwestern habit of not scalping extended at least as far south as the Sinkyone and as far east as the Shasta. The Wintun on the Trinity river are also said to have taken no scalps and may therefore be supposed to have practiced the associated form of war dance. Finally, there is an echo of the Yurok custom from as far away as the Maidu of the northern Sacramento valley, who it is said had a war dance performed by armed negotiators.

The battle weapon of California was the bow. Spears have been mentioned as in use by a number of tribes, but all indications are that they were employed only sporadically in hand to hand fighting, and not for hurling from the ranks. It is probable that they were serviceable in an ambush or early morning rush upon the unsuspecting sleepers in a village. In a set fight the spear could not be used against a row of bowmen.

Southern California used the Pueblo type of war club, a rather short, stout stick expanded into a longitudinal mallet head. This seems to have been meant for thrusting into an opponent's face rather than for downright clubbing. The Mohave at any rate knew a second form of club, a somewhat longer, straight, and heavy stick, which served the specific purpose of breaking skulls. In central California mentions of clubs are exceedingly scarce. If they were used they were probably nothing but suitable sticks. When it came to hand to hand fighting the central Californian was likely to have recourse to the nearest stone. Stones were also favored by the northwestern tribes, but in addition there are some examples of a shaped war club of stone in this region. This club was a little over a foot long and rudely edged, somewhat in the shape of a narrow and thick paddle blade. This type has affiliations with the more elaborate stone and bone clubs used farther north on the Pacific coast.

Slings seem to have been known to practically all the Californians as toys, and in some parts were used effectively for hunting water fowl. The only definite reports of the use of slings in warfare are from the Wintun of Trinity river and the Western Mono; both mountaineers.

The shield, which is so important to the Plains Indian and to the Southwestern warrior, was known in California only to the Mohave, 
the Yuma, and the Diegueno, that is to say, the loeal representatives of the Yuman family. It was a round piece of unornamented hide. There is no reference to symbolism, and it appears to have been carried only occasionally. Not a single original specimen has been preserved. Much as tribes like the Mohave speak of war, they very rarely mention the shield, and its occurrence among them and their kinsmen is of interest chiefly as an evidence that the distribution of this object reached the Pacific coast.

Armor enters the state at the other end, also as an extension from a great extra-Californian culture. It is either of elk hide, or of rods twined with string in waistcoat shape. The rod type is reported from the northwestern tribes, the Achomawi, and the northern mountain Maidu. Elk skin armor has been found among the same groups, as well as the Modoc, Shasta, northern valley Maidu, and Wailaki. These closely coincident distributions indicate that the two armor types are associated, not alternative; and that, confined to the northernmost portion of the state, they are to be understood as the marginal outpost of the extension of an idea that probably originated in the eastern hemisphere and for America centers in the culture of the North Pacific coast.

The greater part of central California appears to have been armorless and shieldless.

\section{RELIGION AND KNOWLEDGE}

\section{SHAMANISM}

The shamanistic practices of California are fairly uniform, and similar to those obtaining among the North American Indians generally. The primary function of the California shaman is the curing of disease. The illness is almost always considered due to the presence in the body of some foreign or hostile object. Only among the Colorado river tribes is there definite record of belief in an abstraction or injury of the soul. The shaman's usual business, therefore, is the removal of the disease object, and this in the great majority of cases is carried out by sucking. Singing, dancing, and smoking tobaceo, with or without the accompaniment of trance conditions, are the usual diagnostic means. Manipulation of the body, brushing it, and blowing of tobacco smoke, breath, or saliva-the last especially among the Colorado river tribes-are sometimes resorted to in the extraction of the disease object. 
As contrasted with the general similarity of the practices of the established shaman, there is a considerable diversity of methods employed by the prospective shaman in the acquisition of his supernatural powers. This diversity is connected with a variety of beliefs concerning guardian spirits.

In central California, from the Wailaki and Maidu to the Yokuts, the guardian spirit is of much the same character as with the Indians of the central and eastern United States, and is obtained in a similar way. A supernatural being or animal or other form is seen and conversed with during a trance or dream. Sometimes the spirits come to a man unsought, occasionally there is an avowed attempt to acquire them.

For southern California, information on these matters is still tantalizingly scant, which may indicate that beliefs are meager. The sources of shamanistic power seem to have been deities, monsters, or heavenly phenomena more often than animals or unnamed spirits. Repeated dreams, especially in childhood, seem to produce shamans among the Cahuilla more often than unique experiences of trance or vision type. This is probably an approximation to the point of view of the tribes on the Colorado. It must not be overlooked that the concept of a definite guardian spirit and the institution of shamanism in its common American form are weakly developed among the tribes of the Southwest, especially the Pueblos.

Among the Colorado river peoples it is certain that there was no belief in a guardian spirit of the usual kind. Shamans derived their power by dreaming of the creator or some ancient divinity, or as they themselves sometimes describe it, from having associated before their birth-in other words during a previous spiritual existence-with the gods or divine animals that were on earth at the beginning. The culture of the Colorado river tribes is so specialized that to apply a positive inference from them to the remaining southern Californians would be unsound; but it must be admitted that their status increases the possibility that the latter tribes did not very fully share the central Californian and usual northern and eastern ideas as to the source of shamanistic power.

In northern California, and centering as usual among the northwestern tribes, beliefs as to the source of shamanistic power take a peculiar turn. Among peoples like the Yurok the guardian spirit in the ordinary sense scarcely occurs. The power of the shaman rests not upon the aid or control of a guardian, but upon his maintenance in his own body of disease objects which to non-shamans would be 
fatal. These "pains" are animate and self-moving, but are always conceived as minute, physically concrete, and totally lacking human shape or resemblance. Their acquisition by the shaman is due to a dream in which a spirit gives them to him or puts them in his body. This spirit seems most frequently to be an ancestor who has had shamanistic power. 'The dream, however, does not constitute the shaman as such, since the introduced "pain" causes illness in him as in other persons. His condition is diagnosed by accepted shamans, and a long and rigorous course of training follows, whose object is the inuring of the novice to the presence of the "pains" in his body and to the acquisition of control over them. Fasting and analogous means are employed for this purpose, but the instruction of older shamans seems to be regarded as an essential feature, culminating in what is usually known as the "doctors' dance." This dance is therefore substantially a professional initiation ceremony. There is no doubt that it provided the opportunity for the establishment of shamans' societies as organized bodies; but this step seems never to have been taken in California.

From the Yurok and Hupa this peculiar type of shamanism spreads out gradually, losing more and more of its elements, to at least as far as the Maidu. Already among the Shasta the shaman controls spirits as well as "pains," but the name for the two is identical. With the Achomawi and Maidu the "pain" and the spirit are differently designated. Here, the doctor's concern in practice is more largely with the "pains," but his control of them rests definitely upon his relation to the spirits as such. The doctor dance persists among all these tribes. It is practiced also by the northerly Wintun and the Yuki. The Yuki shamans possess and acquire spirits very much like the central Californians, and these are sometimes animals. The "pain" is still of some importance among them, however, and they and the Wintun agree in calling it "arrowhead." A line running across the state south of the Yuki, and probably through Wintun and Maidu territory about its middle, marks the farthest extension of remnants of the northwestern type of shamanism.

Among the Pomo there is no mention of the doctor dance, while indications of a considerable use of amulets or fetishes suggest that entirely different sets of concepts obtain. The Miwok and Yokuts also knew of nothing like a "doctor dance," and with them it would seem that the Maidu of the south may have to be included, although here direct evidence is not available. 
It may be added that central and southern California are a unit in regarding shamanistic power as indifferently beneficent or malevolent. Whether a given shaman eauses death or prevents it is merely a matter of his inclination. His power is equal in both directions. Much disease, if not the greater part, is caused by hostile or spiteful shamans. Witcheraft and the power of the doctor are therefore indissolubly bound up together. The unsucessful shaman, particularly if repeatedly so, was thought to be giving prima facie evidence of evil intent, and earnest attempts to kill him almost invariably followed. In other cases individuals in a neighboring group were blamed. This was perhaps the most frequent cause of the feuds or - so-called wars of the central and southern Californian tribes.

In the northwest this intertwining of the two aspects of supernatural power was slighter. Shamans were less frequently killed, and then rather for refusal to give treatment or for unwillingness to return pay tendered in treatment, than for outright witchcraft. A person who wished to destroy another had recourse to magical practice. This northwestern limitation of shamanism is probably connected with the fact that among the tribes where it was most marked the shaman was almost invariably a woman. In these matters, too, tribes as far as the Maidu shared in some measure in the beliefs which attained their most clear-cut form among the Yurok and Hupa.

The use of supernatural spirit power was on the whole perhaps more largely restricted to the treatment or production of disease in $\downarrow$ California than in most other parts of aboriginal North America. There is comparatively little reference to men seeking association with spirits for success in warfare, hunting, or love, although it is natural that ideas of this kind erop out now and then. There are however three specialties which in the greater part of the state lead to the recognition of as many particular kinds of shamans or "doctors," as they are usually known in local usage. These are rain or weather doctors, rattlesnake doctors, and bear doctors.

The rain doctor seems generally to have exercised his control over the weather in addition to possessing the abilities of an ordinary shaman. Very largely he used his particular faculty, like Samuel, to make impression by demonstrations. All through the southern half of the state there were men who were famous as rain doctors, and the greatest development of the idea appears to have been in the region where central and southern California meet. Control of the weather by shamans was however believed in to the northern limit 
of the state, though eonsiderably less was made of it there. The groups within the intensive northwestern culture are again in negative exeeption.

The rattlesnake doctor is also not northwestern, although tribes as close to the focus of this culture as the Shasta knew him. His business of course was to cure snake bites; in some cases also to pre-r vent them. Among the Yokuts a fairly elaborate ceremony, which ineluded the juggling of rattlesnakes, was an outgrowth of these beliefs. Less important or conspicuous demonstrations of the same sort seem also to have been made among a number of other tribes, since we know that the northern Maidu of the valley had some kind of a public rattlesnake ceremony conducted by their shamans. There appears to have been some inelination to regard the sun as the spirit to which rattlesnake doctors particularly looked.

The bear doctor was recognized over the entire state from the Shasta to the Diegueño. The Colorado river tribes, those of the extreme northwest, and possibly those of the farthest northeastern corner of the state, are the only ones among whom this impressive institution was apparently lacking. The bear shaman had the power to turn himself into a grizzly bear. In this form he destroyed enemies.r The most general belief, particularly in the San Joaquin valley and southern California, was that he became actually transmuted. In the region of the Wintun, Pomo, and Yuki, however, it seems to have been believed that the bear doctor, although he possessed undoubted supernatural power, operated by means of a bear skin and other paraphernalia in which he encased himself. Generally bear shamans were thought invulnerable, or at least to possess the power of returning to life. They inspired an extraordinary fear and yet seem to have been encouraged. It is not unlikely that they were often looked upon as benefactors to the group to which they belonged and as exercising their destructive faculties chiefly against its foes. In some tribes they gave exhibitions of their power; in others, as among the Pomo, the use of their faculties was carefully guarded from all observation. Naturally enough, their power was considered to be derived from bears, particularly the grizzly. It is the ferocity and tenacity of life of this species that clearly impressed the imagination of the - Indians, and a more accurately descriptive name of the caste would be "grizzly-bear shamans."

Throughout northern California a distinction is made between the shaman who sings, dances, and smokes in order to diagnose, in 
other words, is a clairvoyant, and a second class endowed with the executive power of sucking out disease objects, that is, curing sickness. This grouping of shamans has been reported from the Hupa, Wiyot, Nongatl, Yuki, Pomo, and Maidu. It has not been mentioned among more southerly peoples. It thus coincides in its distribution with the concept of the "pain" as a more or less animate and self-impelled thing, and the two ideas can scarcely be interpreted as other than connected. The sucking shaman seems to be rated higher than the one that only sings; as is only natural, since his power in some measure presupposes and includes that of his rival. It is not unlikely, however, that certain singing shamans were believed to possess a special diagnostic power over illness, and no doubt all such matters as finding lost objects and foretelling the future were their particular province.

\section{CULT RELIGIONS}

The cults or definitely formulated religions of California are too intricate to be described here, so that the following discussion is confined to their interrelations and certain questions of broader aspect. The respective ranges of the four cults are plotted on map 2.

It appears from this map that the specific northwestern cultus is separated from that of north central California by a belt of tribes that participate in neither.

The religions of north central and southern California, or Kuksu and "toloache" cults, on the other hand, seem to have overlapped in the region of the northern Yokuts and Salinans. It is unlikely that the two cults existed side by side with undiminished vigor among the same peoples; one was probably much abbreviated and reduced to subsidiary rank while the other maintained itself in flourishing or at least substantially full status. Unfortunately the tribes that seem to have shared the two religions are the very ones whose culture has long since melted away, so that data are exceedingly elusive. It is not improbable that fuller knowledge would show that the religions reacted towards each other like the basketry complexes that have been discussed: namely, that they were only partially preserved but without mixture.

This seems on the whole to be what has happened in southern * California, where the jimsonweed or "toloache" religion emanating from the Gabrielino and the system of song-myth cycles issuing from the Colorado river tribes existed side by side to only a limited extent among the Diegueño and perhaps some of the Cahuilla and Serrano. 
RITUAL CULTS

NORTHWESTERN : Dances of Wealth Display 〜. L Limits

Wumlus White Deerskin and Jumping Dances

WIIIS One dance only

$x$ Known to be lacking

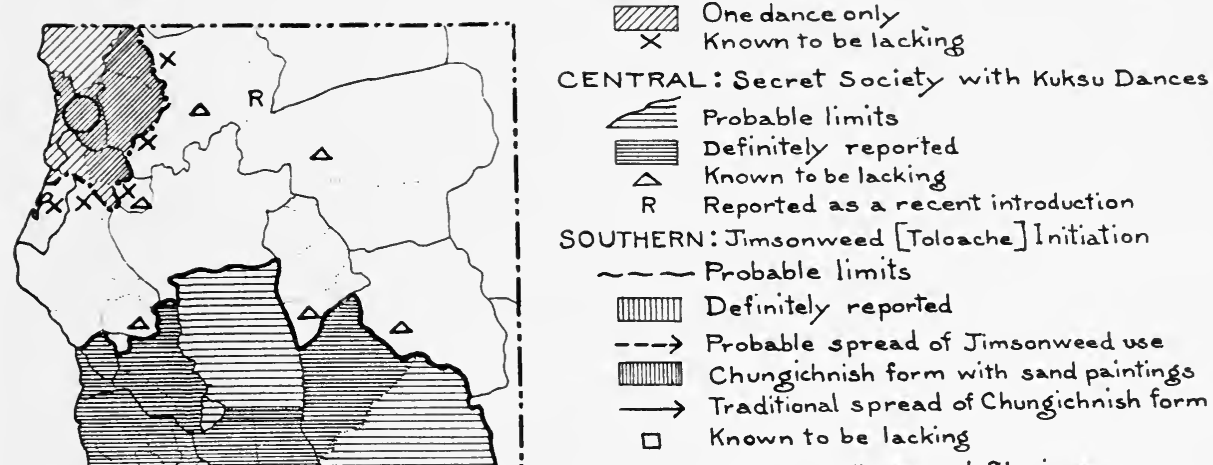

COLORADO RIVER: Dreamed Singings

..... Probable limits
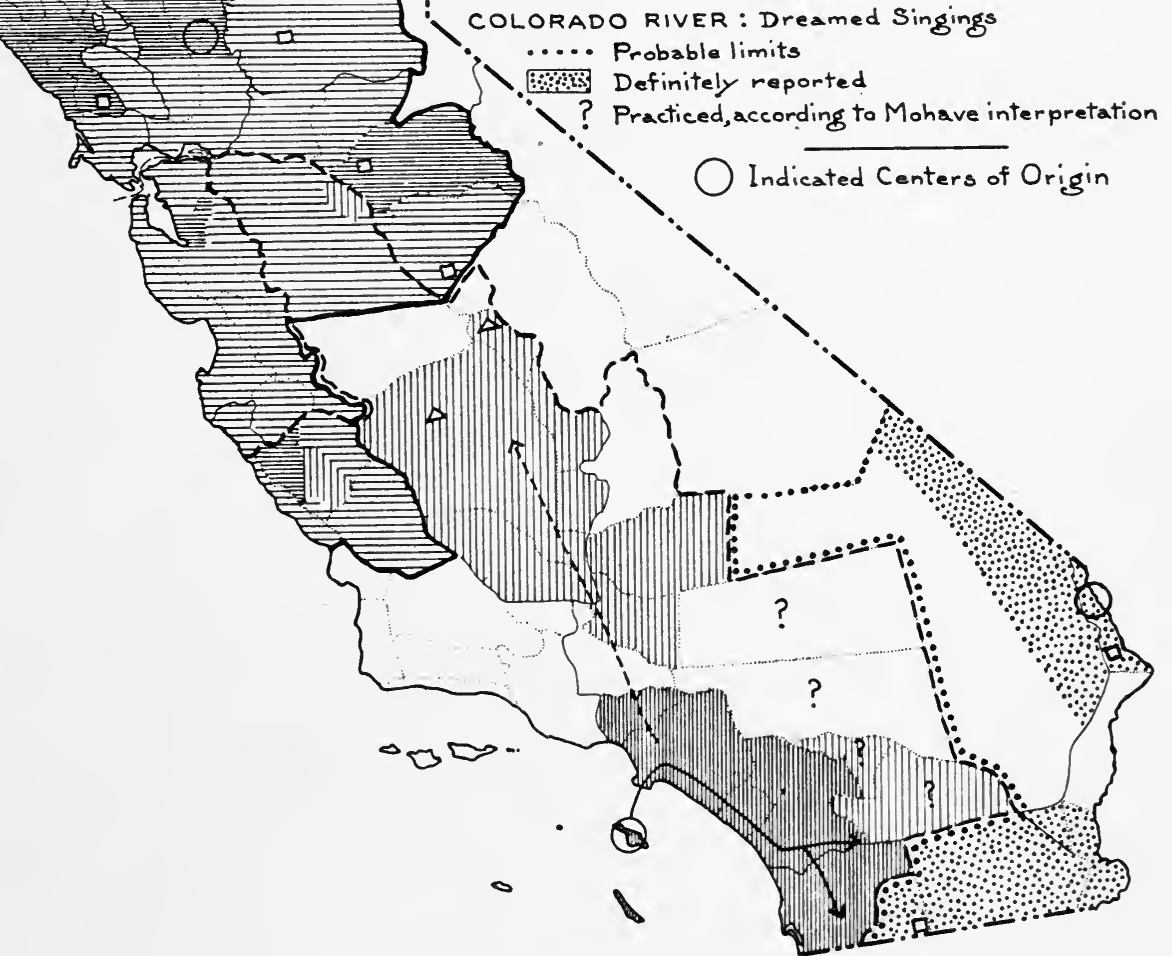

Map 3 
Even in these cases of partial mixture it is possible that the condition is not ancient. A recent wave of propaganda for the jimsonweed cult radiated southward and perhaps eastward from the Gabrielino during mission times-may in fact have succeeded in then gaining for the first time a foothold, particularly when Christian civilization had sapped the strength of the older cults in regions where these had previously been of sufficient vitality to keep out this toloache religion.

In any event there are certain ceremonies of wide distribution in California which must be considered as belonging to a more generalized and presumably older stratum of native civilization than any of the four cults here referred to. Most prominent among these simpler rituals is the adolescence ceremony for girls. The dance of war or victory occupies second place. To this must be added in northwestern and north central California the shamans' dance for instruction of the novice, and in north and south central California various exhibitions by classes or bodies of shamans. Generally speaking, all these rites are dwarfed among each people in proportion as it adheres to one of the four organized cults; but they rarely disappear wholly. They are usually somewhat but rather lightly colored by ritualistic ideas developed in the greater cults. Thus the adolescence rites of the Hupa, the Maidu, and the Luiseño are by no means uniform. And yet, with the partial exception of the latter, they have not been very profoundly shaped by the cults with which they are in contact, and can certainly not be described as having been incorporated in these cults. In short, these old or presumably ancient rites-which are all animated by essentially individual motives as opposed to communal or world purposes-evince a surprising vitality which has enabled them to retain certain salient traits during periods when it may be supposed that the more highly florescent great religions grew or were replaced by others.

The mourning anniversary belongs to neither class and is best considered separately.

The Kuksu and toloache systems shared the idea of initiation into - a society. This organization was always communal. The aim normally was to include all adult males, and even where some attempt at discrimination was made, as perhaps among the Wintun, the proportion of those left out of membership seems to have been small. Nowhere was there the institution of distinct but parallel or equivalent fraternal religious bodies. The organization of the society was of very simple character, particularly in the south. In the Kuksu 
society two grades of initiates were recognized, besides the old men of speeial knowledge who acted as directors.

The Kuksu cult was the only one in California which directly impersonated spirits and had developed a fair wealth of distinctive paraphernalia and disguises for several mythic characters. This is 2 a feature which probably grew up on the spot. It cannot well have reached central California from either the Southwestern or the North Pacific coast areas, since the intervening nations for long distances do not organize themselves into societies; not to mention that the quite diverse northwestern and toloache religions are present as evidences of growths that would have served to block the transmission of such influences as disguises.

To compensate for the simplicity of organization in the Kuksu and toloache religions, initiation looms up largely, according to some reports almost as if it were the chief function of the bodies. Novices were often given a formal and prolonged education. Witness the woknam, the "lie-dlance" or "school," of the Yuki; the orations of the Maidu and Wintun; the long moral lectures to Luiseño boys and girls. That these pedagogical inclinations are an inherent part of the idea of the religious society, is shown by the fact that the Yurok and Mohave, who lack societies, do not manifest these inclinations, at least not in any formal way. In the Southwest, education is much less important than in California, relatively to the whole scheme of the religious institution; and for the Plains the difference is still greater. It appears that these two aspects, initiation and organization, tend to stand in inverse ratio of importance in North American cult societies.

Police and military functions of religious societies are very strongly marked among the Plains tribes; are definitely exercised by the bow or warrior societies of the Southwest; and perhaps stand out larger in native consciousness than in our own, since ethnologists have often approached the religious bodies of the area from the side of cult rather than social influence. But such functions are exceedingly vague and feeble in California. There may have been some regulation of profane affairs by the body of initiates; but the chiefs and other civil functionaries are the ones usually mentioned in such matters in California. There certainly was no connection of the cult societies with warfare. The first traces of a connection between war and ritual appear on the Colorado river, where societies do not exist. The negativeness of the California religious bodies in regard of police 
functions is to be construed as an expression of their lack of development of the organization factor.

In spite of their performance of communal and often public rituals, American religious societies are never wholly divorced from shamanism, that is, the exercise of individual religious power, and one of their permanent foundations or roots must be sought in shamanism. On the Plains, there is a complete transition from societies based on voluntary affiliation, purchase, age, war record, or other non-religious factors, to such as are clearly nothing but more or less fluctuating groups of individuals endowed with similar shamanistic powers. Farther east, the Midewiwin is little more than an attempt at formal organization of shamanism. In the Southwest, among the Pueblos, the fraternal as opposed to the communal religious bodies can be looked upon, not indeed as shamans' associations, but as societies one

$\rightarrow$ of whose avowed purposes--perhaps the primary one-is curative, and which have largely replaced the shaman acting as an individual. Among the Navaho, the greatest ceremonies seem to be curative. In Califormia we have the similarity of name between the Luiseño shaman and initiates-pul-a and $p u-p l-e m$; and the lit or doctoring of the Yuki societies is practically their only function besides that of perpetuating themselves by initiation. In spite of their loose structure and comparative poverty of ritual, it cannot however be maintained that the societies of California are more inclined to be shamanistic than those of the other two regions; and they are less shamanistic in character than the North Pacific coast societies.

Perhaps the most distinctive single trait of the two Californian cult societies is their freedom from any tendency to break up into, or to be accompanied by, smaller and equivalent but diverse societies as in the Plains, Southwest, and North Pacific coast regions.

The cults of the Colorado river tribes are bare of any inclination toward the formation of associations or bodies of members. They rest on dreams, or on imitations of other practitioners which are fused with inward experiences and construed as dreams. These dreams invariably have a mythological cast. Ritually the cults consist essentially of long series of songs; but most singers know a corresponding narrative. Dancing is minimal, and essentially an adjunct for pleasure. Concretely expressed symbolism is scarcely known: disguises, ground paintings, altars, religious edifices, drums or paraphernalia, and costumes are all dispensed with. 
The northwestern cults adhere minutely to certain traditional forms, but these forms per se have no meaning. There is no trace of any cult organizations. The esoteric basis of every ceremony is the reeitation of a formula, whieh is a myth in dialogue. The formulas are jealously guarded as private property. Major rites always serve a generic communal or even world-renewing purpose, and may well be described as new year rites. Dance costumes and equipments are splendid but wholly unsymbolic. All performances are very rigorously attached to precise localities and spots.

It appears that as these four cults are followed from northwestern California southeastward to the lower Colorado there is a successive weakening of the dance and all other external forms, of physical apparatus, of association with particular place or edifice; and an increase of personal psyehic participation, of symbolism and mysticism, of speculation or emotion about human life and death, and of intrinsic interweaving of ritualistic expression with myth. The development of these respective qualities has nothing to do with the development of principles of organization, initiation, and impersonation or enactment; since the latter principles are adhered to in the middle of our area and unknown at the extremities.

\section{THE MOURNING ANNIVERSARY}

The anniversary or annual ceremony in memory of the dead bulks so large in the life of many California tribes as to produce a first impression of being one of the most typical elements of Californian culture. As a matter of fact, the institution was in force over only about half of the state: southern California and the Sierra Nevada region. There can be little doubt that its origin is southern. The distribution itself so suggests. The greatest development of mourning practices is found among the Gabrielino, Luiseño, and Diegueño. It is not that their anniversary is much more elaborate than that of other groups-the use of images representing the dead is common to the great majority of tribes-but these southerners have a greater number of mourning rites. Thus the Luiseño first wash the clothes of the dead, then burn them, and finally make the image ceremony. Of this they know two distinct forms, and in addition there are special mourning rites for religious initiates, and the Eagle dance which is also a funerary ceremony. Another circumstance that points to southern origin is the fact that the anniversary is held by nearly all tribes 
in a circular brush enclosure, such as is not used by the Miwok and Maidu for other purposes, whereas in southern California it is the only and universal religious structure. Finally, there are no known connections between the anniversary and the Kuksu cult of the Miwok and Maidı, whereas the toloache religion of southern California presents a number of contacts with the mourning ceremony.

It is a fair inference that the anniversary received its principal development among the same people that chiefly shaped the toloache cult, namely, the Gabrielino or some of their immediate neighbors. It is even possible that the two sets of rites flowed northward in conjunction, and that the anniversary outreached its mate because the absence or rarity of the jimsonweed plant north of the Yokuts checked the invasion of the rites based specifically upon it.

The Mohave and Yuma follow an aberrant form of mourning which is characteristic of their isolated cultural position. Their ceremony is held in honor of distinguished individual warriors, not for the memory of all the dead of the year. The mourners and singers sit under a shade, in front of which young men engage in mimic battle and war exploits. There are no images among the Mohave and no brush enclosure. The shade is burned at the conclusion, but there is no considerable destruction of property such as is so important an element of the rite elsewhere in California.

An undoubted influence of the anniversary is to be recognized in a practice shared by a number of tribes just outside its sphere of distribution: the Southern Wintun, Pomo, Yuki, Lassik, and perhaps others. These groups burn a large amount of property for the dead at the time of the funeral.

Some faint traces, not of the mourning anniversary itself indeed, but rather of the point of view which it expresses, are found even among the typical northwestern tribes. Among the Yurok and Hupa custom has established a certain time and place in every major dance $\checkmark$ as the occasion for an outburst of weeping. The old people in particular remember the presence of their departed kinsmen at former presentations of this part of the ceremony, and seem to express their grief almost spontaneously.

On the question of the time of the commemoration, more information is needed. It appears rather more often not to fall on the actual anniversary. Among some of the southern tribes it may be deferred some years; with the Mohave it seems to be held within a few weeks or months after death; the Sierra tribes mostly limit it to a fixed season-early autumn. 


\section{GIRLS' ADOLESCENCE CEREMONY}

Probably every people in California observed some rite for girls at the verge of womanhood: the vast majority celebrated it with a dance of some duration. The endless fluctuations in the conduct of the ceremony are indicated in table 1 . It appears that in spite of a general basic similarity of the rite, and the comparatively narrow seope imposed on its main outlines by the physiological event to which it has reference, there are very few features that are universal. These few, among which the use of a head serateher and the abstention from flesh are prominent, are of a specifically magical nature. The wealth of particular features restricted to single nations, and therefore evidently developed by them, is rather remarkable, and argues that the native Californians were not so much defieient in imagination and originality as in the ability to develop these qualities with emotional intensity to the point of impressiveness. There is every reason to believe that this inference applies with equal foree to most phases of Californian eivilization. It merely happens that an unusually full series of details is available for comparison on the rite for girls.

Poor and rude tribes make much more of the adolescence ceremony than those possessed of considerable substance and of institutions of some specialization. In this connection it is only necessary to cite the Yurok as contrasted with the Sinkyone, the Pomo as against the Yuki, the valley Maidu against those of the mountains, the Yokuts against the Washo, the Mohave against the Diegueño. Precedence in general elaboration of culture must in every instance be given to the former people of each pair: and yet it is the second that makes, and the first that does not make, a public adolescence dance. This condition warrants the inference that the puberty rite belongs to the generic or basic stratum of native eulture, and that it has decayed among those nations that succeeded in definitely evolving or establishing ceremonials whose associations are less intimately personal and of a more broadly dignified import.

In the northern half of the state the idea is deeprooted that the potential influence for evil of a girl at the acme of her adolescence is very great. Even her sight blasts, and she is therefore covered or concealed as much as possible. Everything malignant in what is specifically female in physiology is thought to be thoroughly intensified at its first appearance. So far as known, all the languages of this portion of California possess one word for a woman in her periodic 


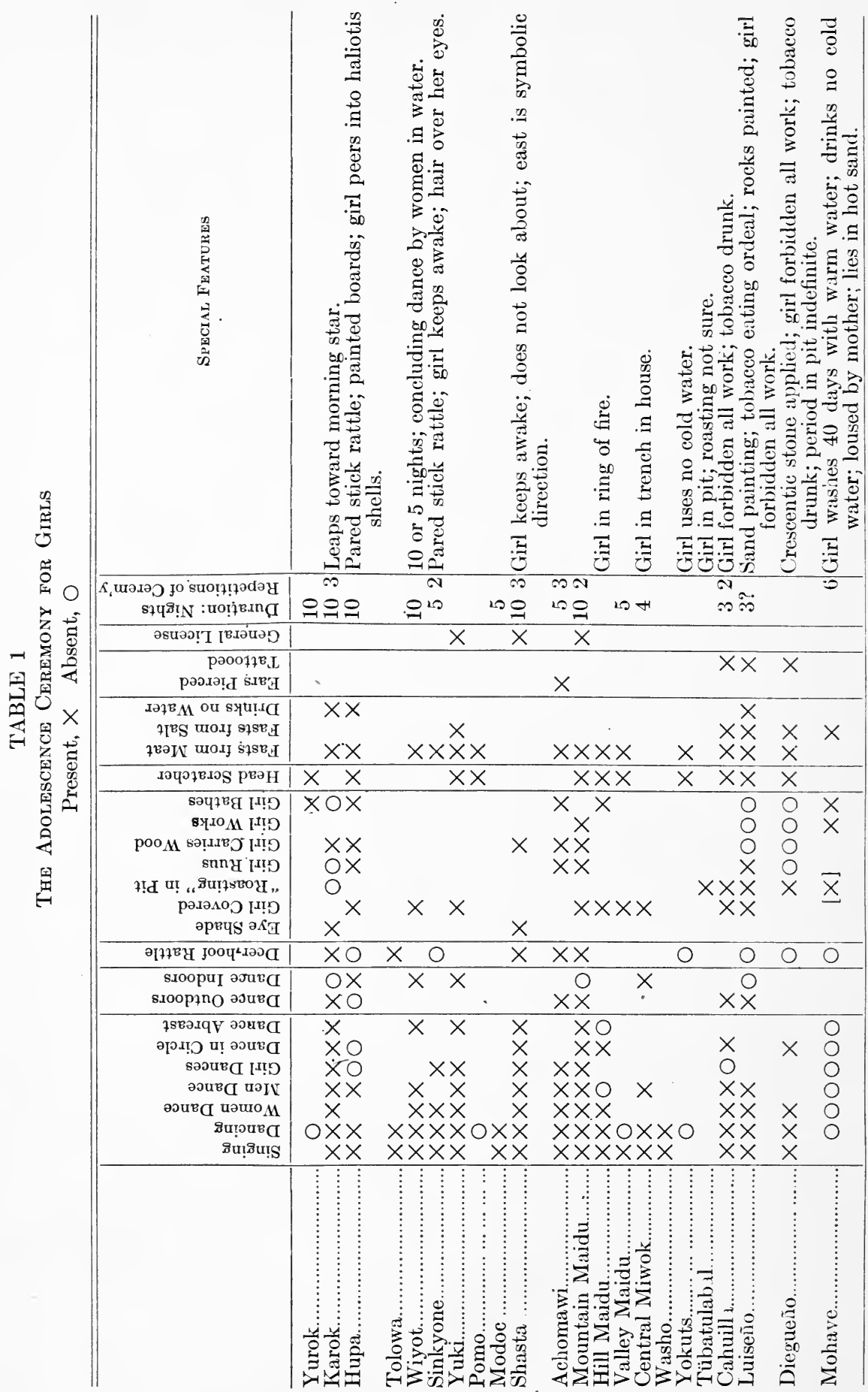


illness; and an entirely distinct term for a girl who is at the precise incipiency of womanhood.

A second concept is also magical : that the girl's behavior at this period of intensification is extremely critical for her nature and conduct forever after. Hence the innumerable prescriptions for gathering firewood, industry, modest deportment, and the like.

This concept pervades also the reasoning of the tribes in the southern end of the state, but is rather overshadowed there by a more special conviction that direct physiological treatment is necessary to ensure future health. Warmth appears to be considered the first requisite in the south. Cold water must not be drunk under any eircumstances, bathing must be in heated water; and in the sphere of Gabrielino-Luiseño influence, the girl is cooked or roasted, as it were, in a pit, which is clearly modeled on the earth oven. The idea of her essential malignancy is by comparison weak.

The southern concepts have penetrated in diluted form into the San Joaquin valley region, along with so many other elements of culture. On the other hand the Mohave, and with them presumably the Yuma, practice a type of ceremony that at most points differs from that of the other southern Californians, and provides an excellent exemplification of the considerable aloofness of the civilization of these agricultural tribes of the Colorado river.

The deer-hoof rattle is consciously associated with the girls' ceremony over all northern California. Since there is a deep-seated antithesis of taboo between everything sexual on the one hand, and everything referring to the hunt, the deer as the distinctive game animal, and flesh on the other, the use of this particular rattle can hardly be a meaningless accident. But the basis of the inverting association has not become clear, and no native explanations seem to have been recorded.

A few Athabascan tribes replace the deer-hoof rattle by a special form of the clap stick which provides the general dance accompaniment throughout central California, but which is not otherwise used in the northwestern habitat. In southern California the deer-hoof rattle is known, but is employed by hunters among the Luiseño, by mourners among the Yumans.

The scarcity of the ritualistic number four in table 1 may be an aceident of tribal representation in the available data, but gives the impression of having some foundation in actuality and therefore a historical significance. 


\section{BOYS' INITIATIONS}

The description which has sometimes been made of Californian religion as characterized by initiation and mourning rites is not wholly accurate. Mourning customs, so far as they are crystallized into formal and important ceremonies, are confined to a single wave of southern origin and definitely limited distribution-the mourning anniversary. The girls' adolescence rite on the other hand is universal, and clearly one of the ancient constituents of the religion of all California as well as considerable tracts outside.

Boys were initiated into the two great organized religions of the $r$ state, the Kuksu and the toloache cult. Important as the initiation ceremonies were in these cults, it would however be misleading to regard them as primary: the cult has logical precedence, the initiation

$\checkmark$ is a part of it. When therefore we subtract these two religions, there is left almost nothing in the nature of initiation for boys parallel to the girls' adolescence ceremony.

The only clear instance is in the northeastern corner of the state among the Achomawi and Shasta, primarily the former. These people practice an adolescence rite for boys comparable to the more widespread one for girls. Among each of them a characteristic feature is the whipping of the boy with a bow string. The Achomawi also pierce the boy's ears and make him fast, besides which he performs practices very similar to the deliberate seeking after supernatural power indulged in by the tribes of the Plains. The entire affair is very clearly an adolescence rather than an initiation rite, an induction into a status of life, and not into an organized group. It may be looked upon as a local extension to boys of concepts that are universal in regard to girls.

In southern California there is sometimes a partial assimilation sof the boys' toloache initiation and of the girls' adolescence ceremony. Thus the Luiseño construct ground paintings for both, deliver analogous orations of advice to both, and put both sexes under similar restrictions. The Kawaiisu are said to give toloache to both boys and girls.

But these local and incomplete developments are very far from equating the initiations for the two sexes; and neither balances with mourning ceremonies. The girls' adolescence, the boys' initiation into a society, and the mourning anniversary clearly have distinct origins so far as California is concerned, and represent cultural planes. 


\section{NEW YEAR OBSERVANCES}

A first-salmon ecremony was shared by an array of tribes in northern California. The central act was usually the catching and eating of the first salmon of the season; after which fishing was open to all. These features make the ceremony one of public magic. The tribes from which a ritual of this kind has been reported are the Tolowa, Yurok, Hupa, Karok, Shasta, Achomawi, and northern mountain Maidu. The list is probably not complete; but it may be significant that all the groups included in it are situated in the extreme north of the state, whereas salmon run in abundance as far south as San Francisco bay. It thus seems possible that the distribution of the rite was limited not by the occurrence of the fish but by purely cultural associations. Its range, for example, is substantially identical with, that of the northern type of overlaid basketry.

The first-salmon ceremony is clearly a ritual of the new year's type, but is the only widely spread instance of this kind yet found in California. The idea of ceremonial reference to the opening of the year or season seems not to have been wholly wanting in north and central California, especially where the Kuksu religion followed a calendar; but there is no record of this idea having been worked out into a definite ritual concept. In the narrower northwest, it is true, there were first-acorn and world-renewing ceremonies as well as the first-salmon rite, and among the Karok the super-added feature of new-fire making; all with associated dances. This, however, is an essentially local development among the small group of tribes who have advanced the northwestern culture to its most intense status.

In other words, an annual salmon producing or propitiating act of magical nature and of public rather than individual reference is usual in the northern part of the state and is therefore presumably an ancient institution. Among the specifically northwestern tribes this act has become associated with a ritualistic spectacle, the Deerskin or the Jumping dance, which probably had no original connection with the magical performance; after which the combination of magic act and dance has been applied, within the same narrow region, to other occasions of a first fruits or new year's character. 


\section{OFFERINGS}

Offerings of feather wands are reported from the Chumash, the Costanoans, and the Maidu, and may therefore be assumed to have had a considerably wider distribution. The idea is that of the feather stick or prayer plume of the Southwest, and there is probably a historical connection between the practices of the two regions; although this connection may be psychological, that is indirectly cultural, rather than due to outright transmission. This inference is supported by the fact that there is no reference to anything like the offering $\rightarrow$ of feather wands in southern California proper. In fact the practice of setting out offerings of any kind is so sparsely mentioned for $\checkmark$ southern California that it must be concluded to have been but slightly developed. The Californian feather wand was of somewhat different shape from the Southwestern feather stick. It appears usually to have been a stick of some length from which single feathers or at most small groups of feathers were hung at one or two places. $\triangle$ The northwestern tribes are free from the practice.

Another ultimate connection with the Southwest is found in offerings or sprinklings of meal. These have been recorded for the Pomo, the Maidu, the Costanoans, and the Serrano. In some instances it is not clear whether whole seeds or flour ground from them was used, and it is even possible that the meal was sometimes replaced by entire acorns. The southern California tribes should perhaps be included, since the use of meal or seeds in the ground painting might be construed as an offering. The custom seems, however, to have been more or less hesitating wherever it has been reported. It certainly lacks the full symbolic implications and the ritualistic vigor which mark it in the Southwest. Among the Yokuts and probably their mountain neighbors, offerings of eagle down appear to have been more characteristic than those of seeds or meal. The northwestern tribes can be set down as not participating in the custom of meal

$\downarrow$ offerings. They blew tobacco, or dropped incense on the fire.

\section{THE GHOST DANCE}

The ghost dance which swept northern California with some vehemence from about 1870 to 1872 is of interest because of its undoubted connection with the much more extensive and better known wave of religious excitement that penetrated to the Indians of half 
of the United States about 1889, and which left most of the Californians untouched. Both movements had their origin among the North- $r$ ern Paiute of Nevara, and from individuals in the same family. The author of the early prophecies may have been the father, and was at any rate an older kinsman, of Wovoka or Jack Wilson, the later messiah. The ideas of the two movements and their ritual were substantially identical. 'There is thus little doubt that even their songs were similar, although unfortunately these were not recorded for the earlier movement until after its fusion with other eults.

The question arises why the religious infection which originated twice in the same spot in an interval of fifteen or twenty years should at the first occasion have obtained a powerful foothold in northern California alone̊, and on its recrudescence should have penetrated to the Canadian boundary and the Mississippi river. That the Californians remained passive toward the seeond wave is intelligible on the ground of immunity acquired by having passed through the first. But that a religion which showed its inherent potentiality by spreading to wholly foreign tribes should in 1870 have been unable to make any eastward progress and in 1890 sweep like wildfire more than a thousand miles to the east, is remarkable. The explanation seems to be that the bulk of the Indian tribes in the United States in 1870 had not been reduced to the necessary condition of cultural deeay for a revivalistic influence to impress them. In other words, the native civilization of northern California appears to have suffered as great a disintegration by 1870 , twenty or twenty-five years after its first serious contact with the whites, as the average tribe of the central United States had undergone by 1890, or from fifty years to a century after similar contact began. As regards the Plains tribes, among whom the second ghost dance reached its eulmination, the same influence on the breaking up of their old life may be ascribed to the destruction of the buffalo as the sudden overwhelming swamping of the California natives by the gold seekers. In each case an interval of from ten to twenty years elapsed from the dealing of the substantial death blow to the native civilization until the realization of the change was sufficiently profound to provide a fruitful soil for a doctrine of restoration.

Individual tribes had of course been subject to quite various fortunes at the hands of the whites when either ghost dance reached them. But it is also known that they accorded the movement many locally diverse receptions. Some threw themselves into it with an almost 
unlimited enthusiasm of hope; others were only slightly touched or remained aloof. This is very clear from Mooney's classical account of the greater ghost dance, and it can be conjectured that an intensive study would reveal the skeptical or negative tribes to have been so situated that their old life did not yet appear to themselves as irrevocably gone, or as so thoroughly subject to the influences of Caucasian civilization that they had accepted the change as final. Then, too, it must be remembered that the wave, as it spread, developed a certain psychological momentum of its own, so that tribes which, if left to themselves or restricted to direct intercourse with the originators of the movement, might have remained passive, were infected by the frenzy of differently circumstanced tribes with whom they were in affiliation.

Similar phenomena can be traced in the history of the California ghost dance, imperfect as our information concerning it is. The Karok and Tolowa seem to have thrown themselves into the cult with greater abandonment than the Yurok. The Hupa, at least to all intents, refused to participate. This is perhaps to be ascribed to the fact that they were the only tribe in the region leading a stable and regulated reservation life. But it is not clear whether this circumstance had already led them to a conscious though reluctant acceptance of the new order of things, or whether some other specific eause must be sought.

On many of the northermost tribes the effect of the ghost dance was transient, and left no traces whatever. It was perhaps already I decadent when the Modoc war broke out. At any rate it is no longer heard of after the termination of that conflict. How far the Modoc war may have been indirectly fanned by the doctrine, remains to be ascertained. Its immediate occasion seems not to have been religious.

Somewhat farther south, the ghost dance took firmer root among tribes like the Pomo and Southern Wintun, who were beyond the most northerly missions but who had been more or less under mission influence and had also been partly invaded by Mexicans in the period between the secularization and the Americanization of California. The old Kuksu ceremonies were now not only revived but made over. A new type of songs, paraphernalia, and ritual actions came into existence; and these have maintained themselves in some measure until today-more strongly than the aboriginal form of religion. The Wintun at least, and presumably the Pomo also, are still conscious, however, of the two elements in their present cults, and distinguish 
them by name. Saltu are the spirits that instituted the ancient rites, boli those with whom the modern dances are associated.

This amalgamation, strangely enough, resulted in the earrying of the Kuksu religion, at a time when it was essentially moribund, to tribes which in the days of its vitality had not come under its influence. Evidently the ghost dance element acted as a penetrating solvent and carrier. The Central Wintun took the mixed cult over from the Southern Wintun, and the use since 1872 of typical Kuksu paraphernalia as far north as the Shasta of Shasta valley evidences the extent of this movement.

None of the tribes within the mission area seems to have been in the least affected by the ghost dance. This is probably not due to their being Catholies or nominal Catholies, but rather to the fact that their life had long since been definitely made over. Groups like the Yokuts, of whom only portions had been missionized, and these rather superficially, also did not take up the ghost dance. The cause in their instance presumably lay between their geographical remoteness and the fact that most of their intercourse was with missionized tribes.

The Modoc were probably the first California people to receive the early ghost dance from the Northern Paiute (map 4). It is hard to conceive that the Achomawi should have been exempt, but unfortunately there appear to be no records concerning them on this point. The same may be said of the mountain Maidu. From the Modoc, at any rate, the cult was carried to the Shasta. These transmitted it still farther down the Klamath to the Karok. From there it leaped the Siskiyou mountains to the Tolowa, from whom the lower Yurok of the river and of the coast took their beliefs. The upper Yurok were less affected and the Hupa scarcely at all. Here we lose track of the spread of the dance. Probably all the Athabasean tribes between the Whilkut and the Wailaki, at least those that survived in sufficient numbers, came under ghost dance influence, but the direction in which this influence progressed is not certain. It is more likely, however, to have been from the south northward, since the dance appears to have been associated with the erection of large round dance houses of central Californian type. This indicates an approximate Pomo or Southern Wintun source. It has already been mentioned how in the Sacramento valley the ghost dance spread from south to north. To this is may be added that the Yana received the eult from the valley Maidu to the south of them. The question then 
arises how the dance reached the Pomo and Southern Wintun. There is no known information on this point. It may have traveled directly westward from the northern Paiute through the Washo and Southern Maidu. On the other hand, the entry into California may have been at a single point: that is, through the Modoc and Klamath river tribes, from whom the cult spread southward until, reaching its extreme limit among the Southern Wintun, it recrystallized and then flowed back northward. Inquiry among the Southern Maidu and Northern Miwok would probably determine this issue.

It is not known whether any of the Miwok took up the ghost dance. In a number of localities they have during the last generation or so erected circular or octagonal dance houses of wood and without earth covering. These look very much like ghost dance modifications of the old semi-subterranean dance house of the Kuksu cults. About fifty years ago, that is, at or near the time of the ghost dance, the hill Miwok received a number of dances, including some of the Kuksu series, that were new to them. These came from Costanoan territory to the west, but probably represent not so much a persistence of ancient Costanoan ritual as a cult revival among the less thoroughly missionized northern Valley Yokuts or possibly Plains Miwok domiciled at the Costanoan missions, who were original neighbors of the hill Miwok.

The 1890 ghost dance is reported by Mooney, specifically or by implication, for the Achomawi, Washo, Mono, Panamint, Yokuts of Tule river, Luiseño or other "Mission" groups, Chemehuevi, and Mohave. The Washo, Eastern Mono, Chemehuevi, and perhaps Panamint could hardly have escaped participation. The Achomawi may have been rendered susceptible by a failure to take part in 1872 . The Mohave were never seriously affected. The Yokuts and Luiseño were no doubt interested, but seem never to have practiced the cult. No tribe in California retained for more than a very short time any phase of this second ghost dance religion.

\section{CALENDAR}

The California Indian did not record the passage of long intervals of time. No one knew his own age nor how remote an event was that had happened more than half a dozen years ago. Tallies seem not to have been kept, and no sticks notched annually have been reported. Most groups had not even a word for "year," but employed "world," "summer," or "winter" instead. Where there appear to be words meaning "year," they seem to denote "season," that is, a half-year. 


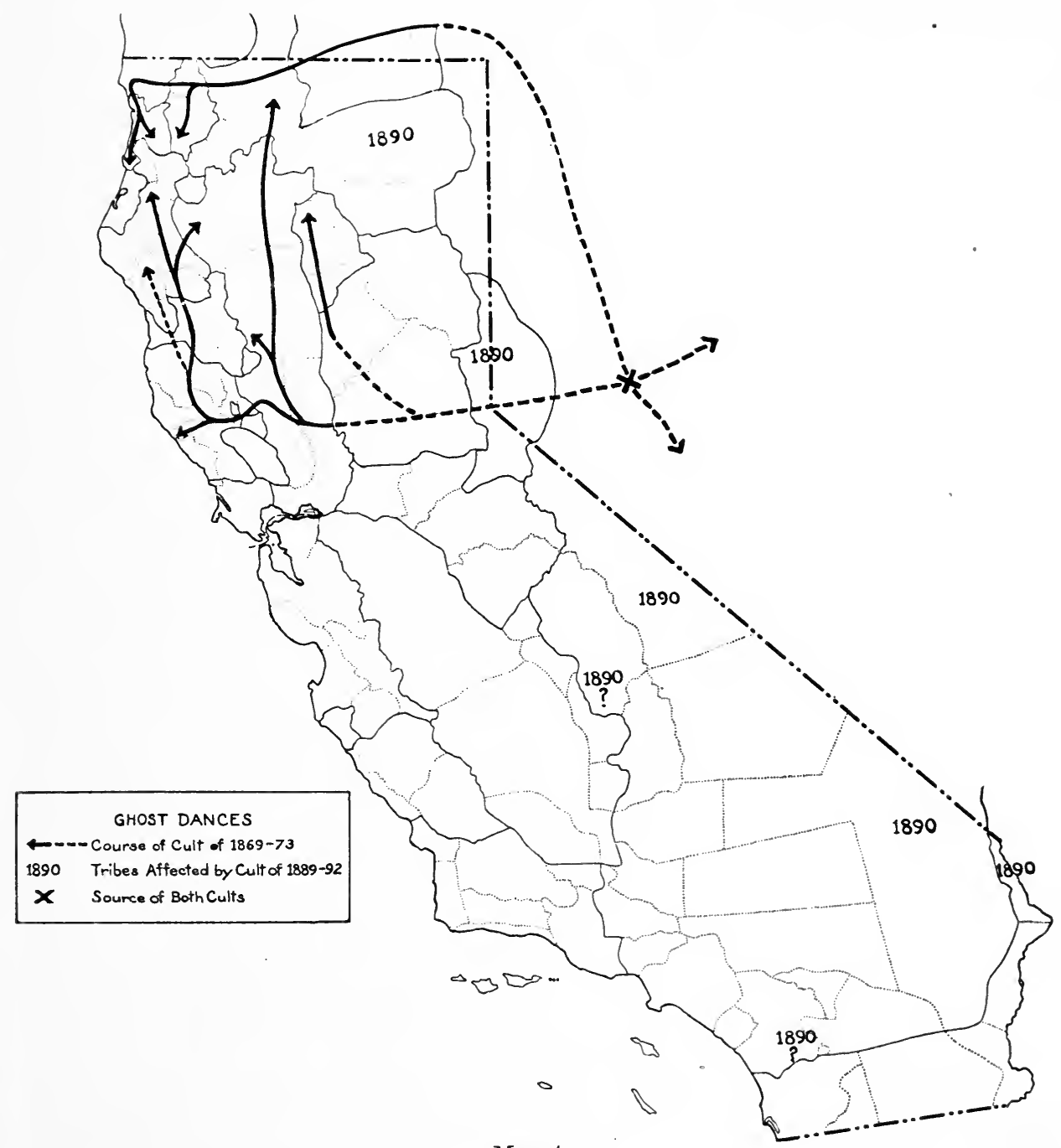

Map 4 
Probably every tribe, however, had a system of measuring time within the year. This was by the universally known method of naming and reckoning lunations within the round of the seasons. The point of interest in this method to the historian of culture rests in the means taken to adjust the eternally varying and essentially irreconcilable lunar and solar phenomena. Half a dozen such calendars are known from California. These clearly belong to three types.

The Maidu, or rather some of them, knew twelve moons, named after seasonal occurrences. The series began in spring, and appears not to have been controlled by any solar phenomenon. There can accordingly scarcely have been a consistent method, however rude, of adjusting the moon count to the year. When the discrepancy became too insistent, something was presumably stretched or the reckoning simply suspended until matters tallied again. The whole scheme is essentially descriptive of terrestrial events, and has as little reference to astronomical events as a system can have and still be called a calendar. In line with this attitude of the Maidu is the fact that they made definite recognition of the seasons as such, as shown by a neat nomenclature. It should also be added that some of the upland Maidu counted only the winter moons, those of the summer being left unnamed.

The few other central Californian calendars known do not differ in plan from those of the Maidu.

The Yurok calendar had a more astronomical basis, although simple enough; and the descriptive element was almost lacking. The moons were numbered, not named, at least up to the tenth; the remaining ones had descriptive appellations. The year began definitely at the winter solstice. The summer solstice may have been noted also, but did not enter into the system. There was a clear recognition of the essential problem of a year calendar, some individuals counting twelve moons and others thirteen. The solution must have been less clearly formulated, since it is stated that disputes often took place as to the proper designation of the current moon. Yet the recognition of the solstice as a primary point, however inaccurately it may have been determined by offhand appearances without mechanically aided observations, would prevent any excessively gross errors or long continued conflict of opinion.

The Yurok system is undoubtedly connected with that of the North Pacific coast, where the moons are also frequently numbered and fitted into the frame afforded by the solstices. 
The Modoe calendar seems to be a weakening of the Yurok one. Basically, the moons are numbered, although their actual names are those of the fingers of the hand. But the beginning of the round is in summer and is determined by a seasonal harvest; there is no mention of the solstices; and none of an intercalary thirteenth month.

In southern California, the moon names are probably deseriptive, but the fixed points of the calendar, and the means of its more or less automatic correction, are the two solstices. The Diegueño have only six month names; which means that the second year-half repeats and balances the first. and presumably that the two solstices are pivotal. The Juaneño and Luiseño do not repeat month designations within the year, but the former name only five and the latter but four lunations in each rear-half. This scheme makes the non-lunar periods that include the solstices long and somewhat variable, but also accentuates them as primary. All three varieties of this calendar must at times have been productive of difficulty within the year-half, but as a perpetual system the scheme is obviously self-correcting. Whether any of the southern California tribes took actual observations of the solstices is not known.

This southern calendar is clearly allied to that of the tribes of the southwestern states, who also deal in solstices but describe their moons. The Diegueño six-name plan is that of the Zuñ. The Pueblos definitely determined the solstices with fair accuracy by observations made on the horizon from established spots. It is possible that they were led to this procedure by their permanent residences. These would at least afford an advantage and perhaps a stimulus in this direction.

Astronomical knowledge not directly used in time reckoning was slight in northern and central California. The planets were too difficult to trouble with, except for Venus when it was the morning star. The Pleiades are the constellation most frequently mentioned, and seem to have had a designation among every tribe. Myths usually make them dancing girls, as in so many parts of the world. This may prove to be one of the concepts of independent or directly psychological origin which have so often been sought but are so difficult to establish positively. Orion's belt is probably recognized with the next greatest frequency, and then possibly Ursa Major. There are some references to Polaris as the immovable star. The Milky Way is known everywhere, and quite generally called the ghosts' road. In southern 
California stellar symbolism begins to be of some consequence, and a half-dozen constellations are named in addition to those recognized farther north. They are mostly those of the southern summer sky.

\section{NUMERATION}

The round numbers familiar to the Californians in ritual and myth are low, as among all American Indians. In the north, from the Tolowa and Sinkyone to the Achomawi and mountain Maidu, five or its multiple ten is in universal use in such connections. (Table 2.) In the region of the well defined Kuksu cult, four takes its place, although the Pomo evince some inclination to supplement it by six. To the south, there is enough uncertainty to suggest that no one number stood strongly in the foreground. The Yokuts favor six, but without much emphasis. The Gabrielino employed five, six, and seven in addition to four; among the Juaneño, five is most commonly mentioned; for the Luiseño, probably three; among the Diegueño, three is clearly prevalent in ritual action, four in myth. For a group of American nations with a definite ceremonial cult, and that comprising sacred paintings of the world, this is an unusually vague condition. Only the Colorado river tribes are positive: four is as inevitably significant to them as to all the Indians of the Southwest.

Directional reference of the ritualistic number is manifest in the Kuksu tribes, but everywhere else is wanting or at least insignificant, except with the Yuman groups. Here there is some tendency to balance opposite directions; single pairs are even mentioned alone. North or east has the precedence. In the Kuksu region, there is a definite sequence of directions in sinistral circuit; but the starting point varies from tribe to tribe. Association of colors with the directions has been reported only from the Diegueño. Its general absence is an instance of the comparatively low development of ritualistic symbolism in California.

The same table (2) shows also the distribution in California of methods of counting-the basis of all mathematical science. Mankind as a whole, even when most advanced, counts as its fingers determine. But it is obvious that the unit or basis of numeration can be one hand, or two, or the fingers plus the toes, that is "one man." This gives a choice between quinary, decimal, and vigesimal systems. Whether from an inherent cause or because of a historical accident, practically all highly civilized nations count by tens, with hundred 
TABLE 2

Ritual Numbers and Methods of Numeration

\section{Group}

Yurok

Wiyot

Karok

Chimariko

Tolowa

Hupa, Chilula

Sinkyone

Wailaki

Kato

Coast Yuki

Yuki

Wappo

Pomo

Coast Miwok

Shasta

Modoc

Achomawi

Yana

Wintun, Northern

Wintun, Central

Wintun, Southern

Maidu, Mountain

Maidu, Hill

Maidu, Valley

Maidu, Southern

Miwok, Northern

Miwok, Central

Miwok, Southern

Yokuts, Central

Yokuts, Southerly 3

Costanoan

Esselen

Salinan

Chumash

Washo

Eastern Mono

Tübatulabal

Chemehuevi

\section{Serrano}

Gabrielino

Cahuilla

Luiseño

Diegueño

Yuma

Mohave

\section{Ritual Number}
5, 10
5,10
5, 10

5, 10

5

$4^{*}$

(6)

$4^{*}$

$\left(6^{*}\right)$

5,10

5

(5)

(5)

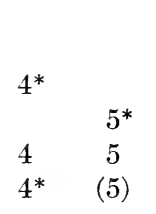

4

6

(5)

6,12

$$
1-10
$$

Units of Count 11-19

$20-$

10

10

10

10

10

10

10

10

5

5

5

5

8

5

$5^{1}$

10

5

5

5

5

5

5

5

5

5

5

5

10

10

10

10

10

$10^{3}$

5

4

4

5

10

10

10

5

$\begin{array}{lll}4,8 & (10) \quad 6\end{array}$

(7)

$\begin{array}{rr}10 & 10 \\ 5 & 5 \\ 10 & 10 \\ 5 & 5 \\ & 10 \\ 10 & 10 \\ 10 & 10\end{array}$

* Referred to cardinal directions.

110 among Northeastern Pomo.

210 among Northeastern and Southern Pomo.

35 among Southern Costanoans. 
as the next higher unit. Peoples less advanced in eulture are however fairly equally divided between a decimal numeration and one which operates somewhat more concretely or personally with fives and twenties. So too with the Californians. But to judge eorrectly their inclinations as between these two possibilities, it is necessary to distinguish between their use of low and high numbers.

For the first ten numerals, the majority of the Californians have stems only for one to five. The words for six to nine are formed from those for one to four. This system is replaced by a truly decimal one, in which the word for seven, for instance, bears no relation to that for two, chiefly in three regions. The first of these regions holds the two Algonkin divisions of California, the Wiyot and Yurok; and a few immediately adjacent Athabascan groups, notably the Hupa and Tolowa. The second area comprises the Yokuts, Miwok, and most of the Costanoans-in short, the southern half of the Penutian family. In the third area are the Plateau Shoshoneans east of the Sierra Nevada.

These distributions reflect geographical positions rather than linguistic affinities. The northern Penutians, southern Athabascans, and southern California Shoshoneans count by fives. The map makes it look as if decimal numeration had been taken over by the Hupa and Tolowa in imitation of the method of their Algonkin neighbors; but the difficulty in this connection is that the great mass of eastern Algonkins count by fives instead of straight to ten.

For the higher numbers, the corresponding choice is between a system based on twenty and four hundred, or on ten and one hundred. In this domain the decimal system prevails, showing that the quinary and vigesimal methods, even if inherently associated, are not inseparable. The situation may be summed up by saying that from twenty up, all California counts decimally except the people of two areas. The first comprises half or more of the Pomo, most of the southern Wintun, in general the western Maidu, and the northerly divisions of the interior Miwok. This is precisely the region of intensive development of the Kuksu cults. Here the count is by twenties. The second area (although in this the count is, strictly speaking, by a multiplication of fives rather than by twenties) is that of the Gabrielino and Luiseño, with whom the Fernandeño, Juaneño, and perhaps Cupeño must be included, but no others. Now this, strangely enough, is precisely the tract over which the Chungichnish form of the jimsonweed religion had penetrated in its full form. The connection between 
a system of religious institutions and a method of numeration in daily life is difficult to understand, and the bonds must be indirect and subtle. That they exist, however, and that it is more than an empty coineidence that we are envisaging, is made almost indisputable by the fact that the northern tract of decimal counting for low numbers coincides very nearly with the area of the northwestern eulture in its purest form as exemplified by new year rites and the Deerskin dance.

That the basing of the vigesimal on a quinary count, although usual, is by no means necessary, is also shown by the Northern and Central Miwok, who count the first ten numbers decimally, but proceed from ten to twenty by adding units of five, and beyond with units of twenty. That a people should count first five and then another five and then proceed to operate systematically with the higher unit of ten, is not so very foreign to our way of thinking. But that our own psychic processes are by no means necessarily binding is proved by this curious Miwok practice of counting successively by tens, fives, and twenties.

Two other, totally divergent methods of counting are found in California. The Chumash and Salinans count by fours, with sixteen as higher unit, the Yuki by eights and sixty-fours. The latter operate by laying pairs of twigs into the spaces between the fingers. Thus the anomaly is presented of an octonary system based on the hand. The Yuki operate quite skilfully by this method: when they are asked to count on the fingers as such, like their neighbors, they work slowly and with frequent errors. Both these aberrant systems run contrary to speech affinity: the Chumash and Salinans are the only. Hokans that count by fours; and the Coast Yuki, Huchnom, and Wappo related to the Yuki know nothing of the system of eights.

Every count that can progress beyond one hand involves arith- metical operations of some sort, usually addition. But other processes crop out with fair frequency in California. Nine, fourteen, and nineteen are sometimes formed from the unit next above. The word for four is often a reduplicated or expanded two; or eight a similar formation from four. Two-three for six, three-four for twelve, and three-five for fifteen all occur here and there; and the Luiseño count by an indefinitely repeated system of multiplication, as, "four times five times five."

The degree to which mathematical operations were conducted, other than in the counts themselves, has been very little examined. The Pomo speak of beads by ten and forty thousands. Every group 
in the state, apparently, knew how to count into the hundreds; how often its members actually used these higher numbers, and on what occasions, is less clear. Rapid and extended enumeration argues some sense of the value of numbers, and it is likely that people like the Pomo and Wintun developed such a faculty by their counting of beads. Of direct mathematical operations there is less evidence. An untutored Yuki can express offhand in his octonary nomenclature how many fingers he has; he evidently cannot multiply ten by two: for he finds it necessary to count his hands twice over to enable him to answer. An old Mohave knows at once that four times four is sixteen; but four times eight presents a problem to be solved only by a sorting and adding up of counters. No Californian language is known to have any expression for fractions. There is always a word for half, but it seems to mean part or division rather than the exact mathematical ratio. 


UNIVERSITY OF CALIFORNIA PUBLICATIONS-(Continuod)

3. Pomo Indian Basketry, by S. A. Barrett. Pp. 133-306, plates 15-80, 231 text figures. December, 1908

4. Shellmounds of the San Francisco Bay Region, by N. C. Nelson. Pp. S09. 356, plates 32-34. December, 1909

5. The Ellis Landing shellmound, by N. C. Nelson. Pp. 357-426, plates 36-50. April, 1910

Index, pp. $427-443$.

V01.8. 1. A Mission Record of the California Indians, from a Mannscript in the Bancroft Library, by A. L. Kroeber. Pp. 1-27. May, 1908

2. The Ethnography of the Cahuilla Indians, by A. I. Kroeber. Pp. 29-68, plates 1-16. Juiy, 1908

3. The Religion of the Luiseño and Diegueño Indians of Southern Californts, by Constance Goddard Dubois. Pp. 69-186, plates 16-19. June, 1908 ......

4. The Culture of the Iuiseño Indians, by Philip Stedman Sparkman. Pp. 187 . 234, plate 20. August, 1908

5. Notes on Shoshonean Dialects of Southern Callfornia, by A. I. Kroeber. Pp. 235-269. September, 1909

6. The Religious Practices of the Diegueño Indians, by T. T. Waterman. Pp. 271-358, plates 21-28. March, 1910 Index, pp. 359-369.

Vo1. 8. 1. Yana Texts, by Edward Sapir, together with Yana Myths collected by Roland B. Dixon. Pp. 1-235. February, 1910

2. The Chumash and Costanoan Languages, by A. I. Kroeber. Pp. 237-271. Novंember, 1910

3. The Languages of the Coast of California North of San Francisco, by A. I. Kroeber. Pp. 273-435, and map. April, 1911 Index, pp. 487-439.

V01. 10. 1. Phonetic Constituents of the Native Languages of California, by A. I. Kroeber. Pp. 1-12. May, 1911

2. The Phonetic Elements of the Northern Pafute Language, by T. T. Waterman. Pp. 13-44, plates 1-5. November, 1911

3. Phonetic Elements of the Mohave Ianguage, by A. I. Kroeber. Pp. 45-96, plates 6-20. November, 1911

4. The Ethnology of the Salfnan Indians, by J. Alden Mason. Pp. 97-240, plates 21-37. December, 1912

5. Papago Verb Stems, by Juan Dolores. Pp. 241-263. August, 1913 ............

6. Notes on the Chilula Indians of Northwestern Callfornis, by Pling Earlo Goddard. Pp. 265-288, plates 38-41. April, 1914

7. Chilula Texts, by Pliny Earlo Goddard. Pp. 289-379. November, $1914 \ldots$ Index, pp. 381-385.

Vol 11. 1. Elements of the Kato Ianguage, by Pliny Earlo Goddard. Pp. 1-176, plates 1-45. October, 1912

2. Phonetic Elements of the Diegueño Language, by A. I. Kroeber and J. $\mathbf{P}$. Harrington. Pp. 177-188. April, 1914

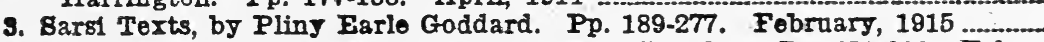

4. Serian, Tequistlatecan, and Hokan, by A. I. Kroeber. Pp. 279-290. Fobruary, 1915

5. Dichotomous Social Organization in South Central Callfornia, by Edward Winslow Gifford. Pp. 291-296. February, 1916

6. The Delineation of the Day-Signs in the Aztec Manuscripts, by T. T. Waterman. Pp. 297-398. March, 1916

7. The Mutsun Dialect of Costanoan Based on the Vocabulary of De la Cuesta, by J. Alden Mason. Pp. 399-472. March, 1916 Index, pp. 473-479.

V01. 12. 1. Composition of California Shellmounds, by Edward Winslow Giford. Pp. 1-28. February, 1916

2. Callfornta Place Names of Indian Origin, by A. Z. Kroober. Pp. \$1-69. June, 1916

3. Arapaho Dialects, by A. I. Kroeber. Pp. 71-138. June, $1916 \ldots$

4. Miwok Moleties, by Edward Winslow Gifford. Pp. 139-194. June, 1916...

5. On Plotting the Inflections of the Voice, by Cornelius B. Bradley. P 218, plates 1-5. October, 1916

6. Ttibatulabal and Kawalisu Kinship Terms, by Edward Winslow Gifford. Pp. 219-248. February, 1917

7. Bandelier's Contribution to the Study of Anclent Mexican Social Organization, by T. T. Waterman. Pp. 249-282. February, 1917

8. Miwok Mvths, by Edward Winslow Gifford. Pp. 283-338, plate 6. May, 1917

9. California Kinship Systems, A. L. Kroeber. Pp. 339-396. May, 1917

10. Ceremonies of the Pomo Indians, by S. A. Barrett. Pp. 397-441, 8 text figures. July, 1917

11. Pomo Bear Doctors, by 8. A. Barrett. Pp. 443-465, plate 7. July, $1917 \ldots$ Index, pp. 467-473. 
RETURN CIRCULATION DEPARTMENT

TO $\rightarrow 202$ Main Library

4

Vo:

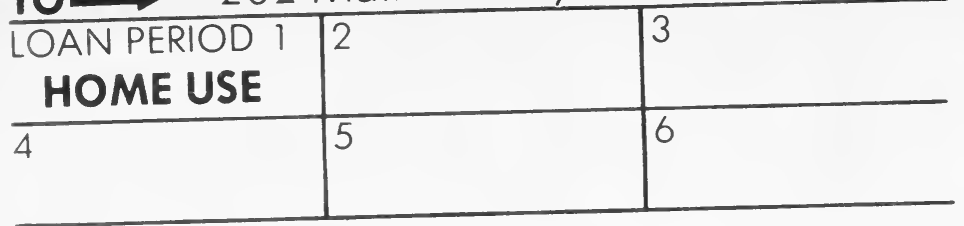

ALL BOOKS MAY BE RECALLED AFTER 7 DAYS

Renewals and Recharges may be made 4 days prior to the due date.

Books may be Renewed by calling 642-3405.

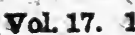

\section{DUE AS STAMPED BELOW}

Vol 15. 1

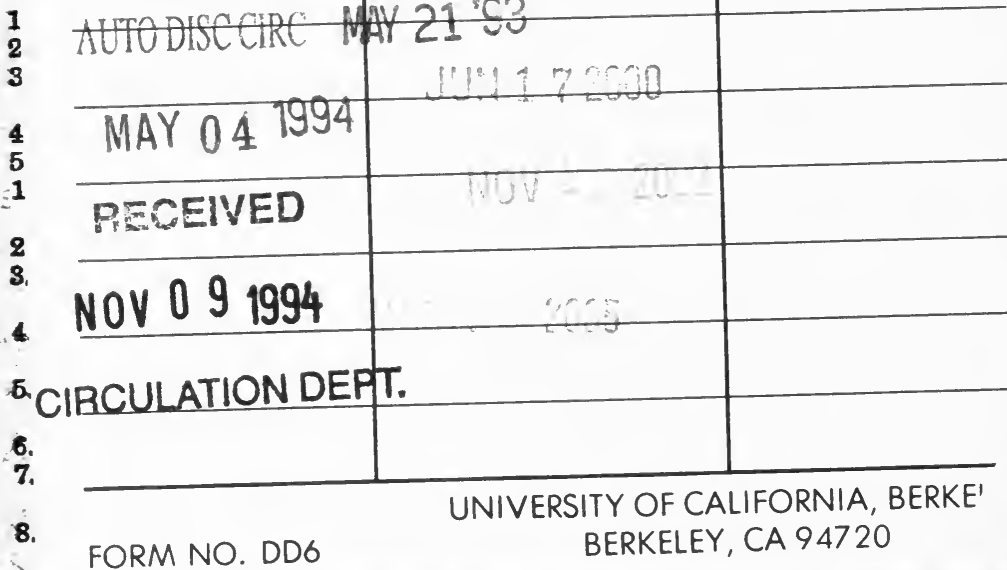

Pad Radin. Pp. 1-150, 17 plates. June, 1920

2. California Cultare Provinces, by A. I. Kroeber. Pp. 151-169, 2 maps. September, 1920 ... Dance Series in Zunil in 1918, by Hisie Clews Parsons.

3. Winter and Summer Dance Series in Zuni in 191
Pp. 171-216, 2 figures in text. Angust, 1922

701 18. 1. Californian Kinship Terminologies, by Edward Winslow Gifford. Pp. 1-285, with 29 maps. December, 1922

Volumes now completed:

Volume 1. 1903-1904. 378 pages and 30 plates

Volume 2. 1904-1907. 393 pages and 21 plates

Volume 3. 1905. The Morphology of the Hups Language, 314 pages

Volumo 4. 1906-1907. 374 pages, with 5 tables, 10 plates, and map

Volume 5. 1907-1910. 384 pages, with 25 plates

Volume 6. 1908. 400 pages, with 3 maps

Volume 7. 1907-1910. 443 pages and 50 plates

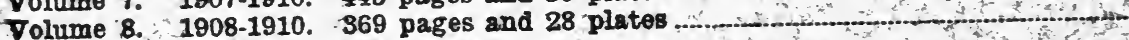

Volume 9. 1910-1911. 439 pages

Volume 10. 1911-1914. 385 pages and 41 plates

Volumo 11. 1911-1916. 479 pages and 45 plates

Volume 12. 1916-1917. 473 peges and 7 plates

Volume 14. 1918-1919. 506 pages and 21 plates

Tote.-The University of Calffornia Publications are pffared in exchange for the publcations of learned societies and institutions, nniversitles and ibraries. Complete lists of all the publications of the University will be ient upon request. For sample caples, Itsts of publications or other 'fnformation, address the MANAGER OF THE UNIVERSITY PRESS, BERKELEY, CAIITORNIA, U. 8. A. All matter sent in exchange should be addressed to THE EXCHANGE DEPARTMENT, UNIVERSIIY LLBRARY, BERKELEY, CAIIFORNIA, U. S.A. 